\title{
Calbindin regulates Kv4.1 trafficking and excitability in dentate granule cells via CaMKII-dependent phosphorylation
}

\author{
Kyung-Ran Kim ${ }^{1,6,7}$, Hyeon-Ju Jeong ${ }^{2,7}$, Yoonsub Kim', Seung Yeon Lee ${ }^{1}$, Yujin Kim ${ }^{1,3}$, Hyun-Ji Kim ${ }^{4}$, Suk-Ho Lee iD ${ }^{1,3,5}$, Hana Cho ${ }^{4}$,
} Jong-Sun Kang ${ }^{{ }^{凶}}$ and Won-Kyung Ho ${ }^{1,3,5} \bowtie$

(c) The Author(s) 2021

\begin{abstract}
Calbindin, a major $\mathrm{Ca}^{2+}$ buffer in dentate granule cells (GCs), plays a critical role in shaping $\mathrm{Ca}^{2+}$ signals, yet how it regulates neuronal function remains largely unknown. Here, we found that calbindin knockout (CBKO) mice exhibited dentate GC hyperexcitability and impaired pattern separation, which co-occurred with reduced $\mathrm{K}^{+}$current due to downregulated surface expression of Kv4.1. Relatedly, manipulation of calbindin expression in HT22 cells led to changes in CaMKII activation and the level of surface localization of Kv4.1 through phosphorylation at serine 555, confirming the mechanism underlying neuronal hyperexcitability in CBKO mice. We also discovered that $\mathrm{Ca}^{2+}$ buffering capacity was significantly reduced in the GCs of Tg2576 mice to the level of CBKO GCs, and this reduction was restored to normal levels by antioxidants, suggesting that calbindin is a target of oxidative stress. Our data suggest that the regulation of CaMKII signaling by $\mathrm{Ca}^{2+}$ buffering is crucial for neuronal excitability regulation.
\end{abstract}

Experimental \& Molecular Medicine (2021) 53:1134-1147; https://doi.org/10.1038/s12276-021-00645-4

\section{INTRODUCTION}

$\mathrm{Ca}^{2+}$ signaling is involved in every aspect of neuronal function, from normal physiology, such as synaptic transmission and memory formation, to the pathogenesis underlying various neurological and psychiatric diseases. Cytosolic $\mathrm{Ca}^{2+}$ buffers are essential components for the maintenance of $\mathrm{Ca}^{2+}$ homeostasis and the shaping of $\mathrm{Ca}^{2+}$ signals $^{1}$. Calbindin- $\mathrm{D}_{28 \mathrm{k}}(\mathrm{CB})$ is a major $\mathrm{Ca}^{2+}$ buffer of mature granule cells (GCs) in the dentate gyrus (DG) of the hippocampus ${ }^{2}$, where half of the $\mathrm{Ca}^{2+}$ buffering is attributable to $\mathrm{CB}^{3}$. $\mathrm{CB}$ is typically a mobile and fast-acting $\mathrm{Ca}^{2+}$ buffer that helps to shape the spatiotemporal extent of $\mathrm{Ca}^{2+}$ signals ${ }^{4}$. Increased CB levels in response to nerve growth factor ${ }^{5}$ and a lack of $C B$ in the degenerated substantia nigra ${ }^{6}$ suggest that $C B$ plays a protective role against excitotoxicity. Interestingly, the expression of $C B$ in the $D G$ is markedly reduced in various pathological conditions that are accompanied by cognitive dysfunction, including Alzheimer's disease $(A D)^{7-9}$ and schizophrenia/bipolar disorder ${ }^{10-12}$. Downregulation of $C B$ in hippocampal excitatory neurons by early life stress is implicated in increased susceptibility to stress-induced memory deficits ${ }^{13}$. However, the current mechanistic understanding of the pathophysiological roles of $\mathrm{CB}$ reduction is poor.

$\mathrm{Ca}^{2+}$ /calmodulin (CaM)-dependent protein kinase II (CaMKII) is a multifunctional serine/threonine protein kinase that is highly concentrated in the brain, and activity-dependent activation of CaMKII plays a central role in synaptic plasticity ${ }^{14}$ and neuronal excitability ${ }^{15,16}$. Abnormal CaMKII activity has been implicated in various neuronal diseases, including schizophrenia ${ }^{11}$, intellectual disability ${ }^{17}$, and $A D^{18}$, highlighting the importance of CaMKII in neuronal function. Calcineurin, a $\mathrm{Ca}^{2+}$-dependent protein phosphatase, plays a critical role in the activity-dependent alteration of synaptic transmission ${ }^{19}$. Intriguingly, $\mathrm{Ca}^{2+}$ buffers affect $\mathrm{Ca}^{2+}$ dependent protein kinase and phosphatase activity, thereby regulating neuronal function. Overexpression of $C B$ was found to promote neuronal differentiation, which was concurrent with CaMKII activation and inhibited by a CaMKII inhibitor ${ }^{20}$, suggesting a link between CaMKII and CB in hippocampal progenitor cells. It is of great interest whether the interplay between CB and CaMKII plays a role in mature neurons.

The DG of the hippocampus has long been postulated to mediate pattern separation by transforming similar inputs into distinct neural representations ${ }^{21-23}$. The sparse activity of GCs has been regarded as essential for the computational function that makes pattern separation possible $22-24$. We have recently discovered that Kv4.1 is a key ion channel for the low-frequency firing of GCs, and mice with Kv4.1 depletion in the DG show impaired pattern separation ${ }^{25}$, highlighting the role of Kv4.1 in DG functions. The regulatory mechanisms of Kv4.1 are an intriguing topic worthy of further investigation.

In this study, we discovered that the GCs in CB knockout (CBKO) mice show increased neuronal excitability along with reduced Kv4.1 activity and CaMKII activation. CB deficiency results in impaired CaMKIl activation, which in turn reduces the surface localization of Kv4.1. CaMKII interacts with and phosphorylates the

${ }^{1}$ Department of Physiology, Seoul National University College of Medicine, Seoul, Korea. ${ }^{2}$ Department of Molecular Cell Biology, Sungkyunkwan University School of Medicine,

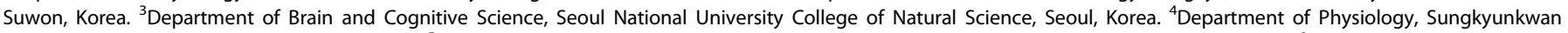

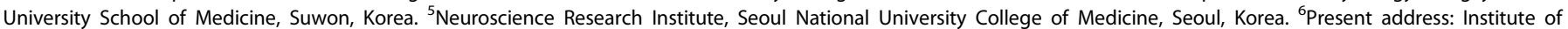
Biolnnovation Research, Kolon Life Science Inc, 110 Magokdong-ro, Gangseo-gu, Seoul 07793, Korea. ${ }^{7}$ These authors contributed equally: Kyung-Ran Kim, Hyeon-Ju Jeong. 凶email: kangj01@skku.edu; wonkyung@snu.ac.kr 
Kv4.1 protein at serine 555 (S555), which regulates its targeting to the membrane and its channel activity. Furthermore, CBKO mice showed impaired pattern separation. Our data collectively suggest that $\mathrm{CB}$ reduction predisposes patients to cognitive dysfunction at least partially by disrupting the CaMKII-dependent regulation of Kv4.1.

\section{MATERIALS AND METHODS}

\section{Preparation of brain slices}

Brain slices were prepared from calbindin- $\mathrm{D}_{28 \mathrm{k}}$ knockout (CBKO) mice (on a C57BL6/J genetic background) and control C57BL6/J mice aged 1-2 months old. CBKO mice were kindly provided by Dr. Schwaller (Univ. of Fribourg, Switzerland). The average ages of CBKO and control C57BL6/J mice used in the present study were $5.6(n=36)$ and 5.7 weeks $(n=10)$, respectively. Experiments for dentate GCs were mostly conducted using mice at postnatal week (PW) 4 to PW 7, while experiments for CA1-PCs were conducted using mice at PW 3 to PW 4. Mice were killed by decapitation after being anesthetized with isoflurane, and the whole brain was immediately removed from the skull and chilled in artificial cerebrospinal fluid (aCSF) at $4{ }^{\circ} \mathrm{C}$. Transverse hippocampal slices $(350-\mu \mathrm{m}$ thick) were prepared using a vibratome (VT1200S, Leica, Germany). Slices were incubated at $35^{\circ} \mathrm{C}$ for $30 \mathrm{~min}$ and subsequently maintained at $32^{\circ} \mathrm{C}$ until in situ slice patch-clamp recordings and fluorescence microscopy. All experimental procedures were conducted in accordance with the guidelines of the University Committee on Animal Resource at Seoul National University (Approval No. SNU-090115-7).

\section{Electrophysiological analysis of excitability and $\mathbf{K}^{+}$currents}

Hippocampal GCs of the DG were visualized using an upright microscope equipped with differential interference contrast (DIC) optics (BX51WI, Olympus, Japan). Electrophysiological recordings were made using the whole-cell clamp technique with an EPC-8 amplifier (HEKA, Lambrecht, Germany). The experiments were performed at $32 \pm 1{ }^{\circ} \mathrm{C}$. After break-in, we waited $5 \mathrm{~min}$ for the neurons to stabilize. The perfusion rate of the bath solution and the volume of the recording chamber for slices were $2.2 \mathrm{~mL} /$ $\mathrm{min}$ and $1.2 \mathrm{~mL}$, respectively. Patch pipettes with a tip resistance of 3-4 M $\Omega$ were used. The series resistance $\left(R_{s}\right)$ after the establishment of the wholecell configuration was between 10 and $15 \mathrm{M} \Omega$. The pipette solution contained the following (in $\mathrm{mM}$ ): $143 \mathrm{~K}$-gluconate, $7 \mathrm{KCl}, 15$ HEPES, 4 Mg-ATP, $0.3 \mathrm{Na}$-GTP, 4 Na-ascorbate, and 0.1 EGTA/or 10 BAPTA, with the $\mathrm{pH}$ adjusted to 7.3 with $\mathrm{KOH}$. For the antibody blocking experiments, patch pipettes were dipped into an internal solution containing anti-Kv4.1 antibodies at a concentration of $0.3 \mu \mathrm{g} / \mathrm{mL}$ and were then back-filled with that solution. The bath solution (or aCSF) for the control experiments contained the following (in mM): $125 \mathrm{NaCl}, 25 \mathrm{NaHCO}_{3}, 2.5 \mathrm{KCl}, 1.25$ $\mathrm{NaH}_{2} \mathrm{PO}_{4}, 2 \mathrm{CaCl}_{2}, 1 \mathrm{MgCl}_{2}, 20$ glucose, 1.2 pyruvate, and 0.4 Na-ascorbate, pH 7.4 when saturated with carbogen $\left(95 \% \mathrm{O}_{2}\right.$ and $\left.5 \% \mathrm{CO}_{2}\right)$. In all bath solutions, $20 \mu \mathrm{M}$ bicuculline and $10 \mu \mathrm{M}$ CNQX were included to block synaptic inputs. In voltage-clamp experiments to record $\mathrm{K}^{+}$currents, we added $\Pi \mathrm{TX}(0.5 \mu \mathrm{M}), \mathrm{CdCl}_{2}(300 \mu \mathrm{M})$, and $\mathrm{NiCl}_{2}(500 \mu \mathrm{M})$ to block $\mathrm{Na}^{+}$and $\mathrm{Ca}^{2+}$ channels, and membrane potentials were depolarized to a maximum of $30 \mathrm{mV}$ for $1 \mathrm{~s}$ in $10 \mathrm{mV}$ increments from the holding potential of $-70 \mathrm{mV}$. In current-clamp experiments to analyze neuronal excitability, the following parameters were measured: (1) the resting membrane potential (RMP), (2) the input resistance ( $R_{i n}$, membrane potential changes $(V)$ for the given hyperpolarizing current $(-35 \mathrm{pA}, 600 \mathrm{~ms})$ input), (3) the F-I curve (firing frequencies (F) against the amplitude of injected currents (I), for DG; 100-600 pA, $100 \mathrm{pA}$ increment, $1 \mathrm{~s}$ duration, for CA1 pyramidal cells (CA1$P(s) ; 50-250 \mathrm{pA}, 50 \mathrm{pA}$ increment, $1 \mathrm{~s}$ duration), and (4) the AP onset time at $300 \mathrm{pA}$ (the delay from the start of $300 \mathrm{pA}$ injection to the beginning of the upstroke phase of the 1st evoked AP). All chemicals were obtained from Sigma (St. Louis, MO, USA), except for CNQX, bicuculline, and TTX, which were obtained from Abcam Biochemicals (Cambridge, UK).

\section{Cytosolic $\mathrm{Ca}^{2+}$ measurement and estimation of calcium- binding ratios}

Cytosolic $\left[\mathrm{Ca}^{2+}\right]$ was measured from fluorescence images of hippocampal GCs in slices loaded with fura-2 (pentapotassium salt). The slices were illuminated using a polychromatic light source (xenon lamp-based, Polychrome, Martinsried, Germany), which was coupled to the epiillumination port of an upright microscope (BX51, Olympus, Japan) via a quartz light guide and a UV condenser, and images were captured with an air-cooled slow-scan CCD camera (SensiCam, PCO, Kelheim, Germany). The monochromator and the CCD camera were controlled by a PC and ITC18, running a custom-made software program written in Microsoft Visual $\mathrm{C}^{++}$ (version 6.0). Details of the calibration method have been described previously ${ }^{26}$.

To estimate the endogenous $\mathrm{Ca}^{2+}$ binding ratio $\left(\mathrm{K}_{\mathrm{E}}\right)$, we applied short depolarizing pulses (from -70 to $0 \mathrm{mV}, 40 \mathrm{~ms}$ in duration) every $20-60 \mathrm{~s}$ to evoke $\left[\mathrm{Ca}^{2+}\right]$ transients in the mature dentate GCs. Normally, $\mathrm{K}_{E}$ is estimated according to the single compartment and linear approximation model ${ }^{27,28}$. When two different $\mathrm{Ca}^{2+}$ buffers, a $\mathrm{Ca}^{2+}$ indicator dye (B) and an endogenous $\mathrm{Ca}^{2+}$ buffer $(\mathrm{E})$, exist in the compartment, the increments of total and free calcium have the following relationship:

$\Delta\left[\mathrm{Ca}^{2+}\right]_{\mathrm{T}}=\Delta\left[\mathrm{Ca}^{2+}\right]_{\mathrm{i}} \cdot\left(1+\kappa_{\mathrm{B}}+\kappa_{\mathrm{E}}\right)$,

where $K_{B}$ and $K_{E}$ are the calcium-binding ratios of $B$ and $S$, respectively. $\mathrm{Ca}^{2+}$ transients $\left(\Delta\left[\mathrm{Ca}^{2+}\right](\mathrm{t}), \mathrm{CaTs}\right)$ following short pulses of $\mathrm{Ca}^{2+}$ influx can be described by the following equations:

$\Delta\left[\mathrm{Ca}^{2+}\right](\mathrm{t})=A \exp (-\mathrm{t} / \tau)$,

$A=\Delta\left[\mathrm{Ca}^{2+}\right]_{\mathrm{T}} /\left(1+\kappa_{\mathrm{B}}+\kappa_{\mathrm{E}}\right)$

$\tau=\left(1+\kappa_{\mathrm{B}}+\kappa_{\mathrm{E}}\right) / \gamma$,

where $A$ is the initial amplitude, $\mathrm{d}\left[\mathrm{Ca}^{2+}\right]_{\mathrm{T}}$ is the total intracellular $\mathrm{Ca}^{2+}$ increase evoked by the influx, $\gamma$ is the $\mathrm{Ca}^{2+}$ extrusion rate, and $\mathrm{K}_{\mathrm{B}}$ is the $\mathrm{Ca}^{2+}$ binding ratio of the $\mathrm{Ca}^{2+}$ indicator dye (fura-2). The calcium-binding ratio of a buffer $\mathrm{X}$ is defined by

$k_{\mathrm{X}}=\partial[\mathrm{CaX}] / \partial\left[\mathrm{Ca}^{2+}\right]=\mathrm{K}_{\mathrm{d}} \cdot \mathrm{X}_{\mathrm{T}} /\left(\left[\mathrm{Ca}^{2+}\right]+\mathrm{K}_{\mathrm{d}}\right)^{2}$,

where $X_{T}$ and $K_{d}$ are the total concentration of $X$ and the dissociation constant of $X$ for $\mathrm{Ca}^{2+}$, respectively ${ }^{28}$. When $\mathrm{K}_{\mathrm{X}}$ is not constant over the dynamic range of $\left[\mathrm{Ca}^{2+}\right]$ in a Ca ${ }^{2+}$ transient, the incremental $\mathrm{Ca}^{2+}$-binding ratio, $\mathrm{K}^{\prime}{ }_{x}$, should be used. This ratio is defined as

$\mathrm{k}_{\mathrm{X}}^{\prime}=\Delta[\mathrm{CaX}] / \Delta\left[\mathrm{Ca}^{2+}\right]=\mathrm{K}_{\mathrm{d}} \cdot \mathrm{X}_{\mathrm{T}} /\left[\left(\left[\mathrm{Ca}^{2+}\right]_{\mathrm{i}, \text { rest }}+\mathrm{K}_{\mathrm{d}}\right) \cdot\left(\left[\mathrm{Ca}^{2+}\right]_{\mathrm{i}, \text { peak }}+\mathrm{K}_{\mathrm{d}}\right)\right]$,

where $\left[\mathrm{Ca}^{2+}\right]_{i, \text { rest }}$ and $\left[\mathrm{Ca}^{2+}\right]_{i, \text { peak }}$ represent the $\left[\mathrm{Ca}^{2+}\right]_{\mathrm{i}}$ value before and at the peak perturbation, $[X]_{T}$ is the total concentration of $\mathrm{Ca}^{2+}$ buffer $\mathrm{X}$, and $\mathrm{K}_{\mathrm{d}}$ is the $\mathrm{Ca}^{2+}$ dissociation constant of $\mathrm{X}^{28}$. According to Eqs. (3) and (4), plotting the $A$ and $\tau$ values measured at different levels of $K_{B}$ provides two estimates of $K_{E}$ : one is obtained from the $x$-intercept of the straight line fitted to the plot of $\tau$ vs. $K_{B}$, and the other is obtained from a line fitted to the plot of $A^{-1}$ vs. $K_{B}$. These two estimates will be referred to as $K_{\mathrm{E}}$.

\section{Cell culture and constructs}

HT22 (Sigma-Aldrich \#SCC129) and HEK293T (ATCC CRL-3216) cells were cultured, as previously described ${ }^{29,30}$. HT22 and HEK293T cells were cultured in DMEM containing 10\% fetal bovine serum (FBS, Gibco) and transiently transfected with a combination of DNA plasmids by using Lipofectamine 3000 (Invitrogen). To examine CB knockdown effects, HT22 cells were infected with a lentivirus carrying the control scrambled-shRNA (5'-CCGGCAACAAGATGAAGAGCACCAACTCGAGTTGGTGCTCTTCATCTTGTT GTITTG-3') or CB-specific shRNA (5'-CCGGGATTGGAGCTATCACCGGAAA CTCGAGTTTCCGGTGATAGCTCCAATCTITITG-3') with polybrene (Sigma) for 2 days. To induce differentiation, cells at $\sim 70-80 \%$ confluence were switched to Neurobasal medium (Gibco) containing N2, B27, GlutaMAX, $5 \mathrm{ng} / \mathrm{mL}$ BDNF, and $50 \mathrm{ng} / \mathrm{mL}$ NGF (Thermo Fisher). The constructs used in this study were as follows: $\mathrm{pCl}$-neo, pCl-neo-CB, Kv4.1-GFP (Origene, MG220056) and GFP-C1-CaMKIla (Addgene, 21226). To examine the role of Kv4.1 phosphorylation, a serine-alanine mutation was introduced at serine residue 265, 555, or 568 of Kv4.1 by using a mutagenesis kit (Stratagene).

The Kv4.1 currents from HEK293T cells were measured with the wholecell patch-clamp technique. A voltage clamp was performed by using an EPC-10 amplifier (HEKA Instrument, Germany), and a $10 \mathrm{kHz}$ filter was applied. The patch pipettes (World Precision Instruments, Inc., USA) were made with a Narishige puller (PP-830, Narishige Co, Ltd., Japan). The patch pipettes used in this study had a resistance of 2-3 $M \Omega$ when filled with the pipette solutions listed in the next sections. All recordings were carried out at room temperature. The normal external solution for HEK293T cell recording was as follows (in mM): $143 \mathrm{NaCl}, 5.4 \mathrm{KCl}, 5 \mathrm{HEPES}, 0.5 \mathrm{NaH}_{2} \mathrm{PO}_{4}$, 11.1 glucose, $0.5 \mathrm{MgCl}_{2}, 1.8 \mathrm{CaCl}_{2}, \mathrm{pH} 7.4$ after adjustment with $\mathrm{NaOH}$. The 
pipette solution was as follows (in $\mathrm{mM}$ ): $135 \mathrm{~K}$-aspartate, $2 \mathrm{MgCl}_{2}, 3 \mathrm{EGTA}, 1$ $\mathrm{CaCl}_{2}, 4 \mathrm{Mg}$-ATP, $0.1 \mathrm{Na}-\mathrm{GTP}, 10$ HEPES, pH 7.4 after adjustment with $\mathrm{KOH}$. Currents were analyzed and fitted using Patchmaster (HEKA Instrument) and Origin 6.1 (Originlab Corp., USA) software. All values are given as the mean \pm SEM. Current-voltage (I/V) relations were obtained by plotting the outward current at $1 \mathrm{~s}$ into the test pulse as a function of the test potential. Current densities $(\mathrm{pA} / \mathrm{pF})$ were obtained after normalization to cell-surface area as calculated by Patchmaster.

\section{Protein analysis and surface biotinylation}

Western blot analysis was performed as previously described ${ }^{25,31}$. Briefly, cells were lysed in RIPA lysis buffer (iNtRON) containing a complete protease inhibitor cocktail (Roche), followed by SDS-PAGE and incubation with primary and secondary antibodies. Primary antibodies against calbindin, p-CaMKIlla, CaMKlla (Cell Signaling), Kv4.1, Kv4.2 (Alomone Lab), GFP (Abcam), and $\beta$-tubulin (Sigma) were used.

Immunoprecipitation was performed as previously described ${ }^{32}$. Briefly, precleared cell extracts were incubated with anti-phosphoserine antibodies (Santa Cruz) overnight at $4{ }^{\circ} \mathrm{C}$, followed by incubation with protein $\mathrm{G}$-agarose beads (Roche) for $1 \mathrm{~h}$. Subsequently, the beads were washed three times with cell extraction buffer, and the precipitates were subjected to western blotting.

Surface biotinylation analysis was carried out as previously described ${ }^{33}$. In brief, the surface proteins of HT22 cells or mouse dentate gyrus were biotinylated by exposure to $1 \mathrm{mg} / \mathrm{mL}$ NHS-LC-biotin (Thermo) for $30-60 \mathrm{~min}$ at $4{ }^{\circ} \mathrm{C}$. After a quenching reaction with $100 \mathrm{mM}$ glycine, cells or dentate gyrus were lysed and sonicated in RIPA lysis buffer (iNtRON) with a proteinase inhibitor (Roche), followed by incubation with streptavidin-agarose beads (Pierce) and western blotting. Immunoreactivity was determined by enhanced chemiluminescence (GE Healthcare). The images were captured using a bioimaging analyzer (LAS-3000; Fuji, Tokyo, Japan) and analyzed with the Multi-Gauge program (Fuji, Tokyo, Japan).

\section{Behavior analysis}

Contextual fear conditioning was performed with male mice between 15 and 16 weeks of age, including 8 CBKO mice. We modified the protocol of McHugh et al. ${ }^{34}$ to conduct the contextual fear discrimination task. Mice were trained to discriminate between two similar contexts, A and B, through repeated experience in each context. Context $A$ (the conditioning context) was a chamber $(18 \mathrm{~cm}$ wide $\times 18 \mathrm{~cm}$ long $\times 30 \mathrm{~cm}$ high; $\mathrm{H} 10-11 \mathrm{M}$ TC; Coulbourn Instruments 5583, PA 18052, USA) consisting of a metal grid floor, aluminum sidewalls, and a clear plexiglass front door and back wall. Context $\mathrm{A}$ was indirectly illuminated with a $12 \mathrm{~W}$ light bulb. The features of Context $B$ (the safe context) were the same as those of Context $A$, except for a unique scent ( $1 \%$ acetic acid), a dimmer light $(50 \%$ of $A)$, and a $15^{\circ}$ slope in the floor. Each context was cleaned with $70 \%$ ethanol before the animals were placed in. On the first 3 days (contextual fear acquisition), the mice were placed in Context $A$ for $3 \mathrm{~min}$ to explore the environment and then received a single footshock $(0.75 \mathrm{~mA}$, for $2 \mathrm{~s})$. The mice were returned to their home cage $1 \mathrm{~min}$ after the shock. On days $4-5$, mice of each genotype were divided into two groups: one group was exposed to Context A on day 4 and Context B on day 5, while the other group was exposed to Context $B$ on day 4 and Context $A$ on day 5. On days 4-5 (generalization), neither group received a shock in Context A or B, and the level of freezing behavior was measured for 5 min only in Context A. We defined freezing behavior as behavioral immobility except for respiratory movement $^{35}$. We observed videos for $2 \mathrm{~s}$ bouts every $10 \mathrm{~s}$ (18 or 30 observation bouts for $3 \mathrm{~min}$ or $5 \mathrm{~min}$ of recording time) and counted the number of $2 \mathrm{~s}$ bouts during which the mouse displayed freezing behavior (referred to as a freezing score). The percentage of freezing was calculated by dividing the freezing score by the total number of observation bouts (18 or 30). The mice were subsequently trained to discriminate between these two contexts by being placed in the two contexts daily for 8 days (from day 6 to day 13, discrimination task). The mice always received a footshock 3 min after being placed in Context $A$ but not $B$. Discrimination ratios were calculated as $F_{A} /\left(F_{A}+F_{B}\right)$, where $F_{A}$ and $F_{B}$ are the freezing scores in Contexts $A$ and $B$, respectively. All experiments and analyses were performed while blinded to the genotypes of the mice.

For one trial of contextual fear conditioning, an experiment was performed with male mice between 14 and 19 weeks of age (eight control mice and eight CBKO mice) in a pair of very distinct contexts ( $A$ and $C$ ). The aforementioned Context $\mathrm{A}$ was used as the conditioning context. The distinct context (Context $\mathrm{C}$ ) was a white acrylic cylinder with a blind end $(15 \mathrm{~cm}$ in diameter, $18 \mathrm{~cm}$ in height, and $0.5 \mathrm{~cm}$ in thickness) standing vertically on the metal grid floor of Context $A$, and the bottom of the cylinder was covered with cage bedding, on which the mice were placed. The chamber and cylinder were cleaned using $70 \%$ ethanol between runs. On day 1 (acclimation), mice were placed in Context A and then placed in Context $C$ an hour later. Mice were allowed to freely explore in both contexts for $5 \mathrm{~min}$. On day 2 (conditioning), all groups of mice were placed in Context $A$ and received a single footshock $(0.75 \mathrm{~mA}$, for $2 \mathrm{~s}) 3 \mathrm{~min}$ later. Mice were left in Context $A$ for $1 \mathrm{~min}$ after the shock. On day 3 (assessment), mice were separated into two groups; the mice of each group were placed in Context $\mathrm{A}$ or $\mathrm{C}$ for 3 min without footshock, during which their freezing scores were measured.

An open-field exploration test was used to assess locomotor activity ${ }^{36}$. Open-field exploration was performed with male mice aged 16 weeks (six control mice and six CBKO mice). Mice were handled before the open-field exploration behavior test (OFT). Mice were picked up by the tail and supported without restraint in the palm of an experimenter's hand for $15 \mathrm{~min} /$ day for 4 days. Following handling, each mouse was placed in a holding cage until all mice had been handled. They were then returned to their home cage. During mouse handling, handlers wore latex gloves, which they changed between mice. After the handling day, we executed the OFT using a modified version of the protocol of Kim et al. ${ }^{36}$. The openfield box was made of white plastic $(40 \times 40 \times 40 \mathrm{~cm})$ and divided into a center zone $(20 \times 20 \mathrm{~cm})$ and an outer field. The entire field was illuminated with diffuse light, and white noise was played in the background. Individual mice were placed in the center zone, and the path of each animal was recorded with a video camera. In a 20 min of observation period, the total distance traveled during the total period and the time spent in the center zone in the initial $5 \mathrm{~min}$ were analyzed using the program EthoVision XT (Noldus, Virginia, USA).

\section{Statistical analysis}

Data were analyzed with IgorPro (Version 6; Wave-Metrics, Lake Oswego, USA) and are presented as the mean \pm SEM with the number of cells or mice $(n)$ used in each experiment. The statistical significance was evaluated using Student's $t$ test, and the level of significance is indicated by the number of asterisks $\left({ }^{*} P<0.05 ;{ }^{* *} P<0.01 ;{ }^{* *} P<0.001\right) . P>0.05$ was regarded as not significantly different (N.S.). Data from behavioral studies were analyzed using IgorPro and Origin (Version 8; Microcal, Northampton, USA). Comparisons between multifactorial statistical data were made using a two-way analysis of variance (ANOVA). The differences in timedependent changes in behavioral parameters between the two genotypes were evaluated using two-way repeated-measures ANOVA.

\section{RESULTS}

\section{Increased excitability in the CBKO GCs}

Reduced $\mathrm{Ca}^{2+}$ buffering may affect the $\mathrm{Ca}^{2+}$ homeostasis of cells. However, the relationship between the extent of $\mathrm{Ca}^{2+}$ buffering and the specific changes in neuronal function is not wellcharacterized. Using CBKO mice, we tested the possibility that $\mathrm{Ca}^{2+}$ dysregulation caused by reduced $\mathrm{Ca}^{2+}$ buffering could alter neuronal excitability in mature GCs of the DG, where CB is a major $\mathrm{Ca}^{2+}$ buffer ${ }^{3}$. To avoid the effect of other $\mathrm{Ca}^{2+}$ buffers in neural progenitor cells and immature newborn neurons, we chose mature GCs located in the outer granular cell layer that had an input resistance $\left(R_{\text {in }}\right)$ lower than $200 \mathrm{M} \Omega$. We confirmed that the average resting membrane potential (RMP; $-81.6 \pm 1.8 \mathrm{mV}, n=9$, for control GCs; $-84.4 \pm 1.0 \mathrm{mV}, n=8$ for CBKO GCs, $P=0.198$ ) and $R_{\text {in }}$ values $(145.1 \pm 11.4 \mathrm{M} \Omega$ for control GCs; $159.1 \pm 13.4 \mathrm{M} \Omega$ for CBKO GCs, $P=0.439$ ) were not significantly different between control and CBKO GCs. Interestingly, we found that the firing frequency in response to long depolarizing pulses was significantly higher in the CBKO GCs (red, Fig. 1a) than in the control GCs (black, Fig. 1a). As a measure of neuronal excitability, we plotted the firing frequencies $(F)$ against the amplitude of the injected currents (I). The F-I relationship was steeper in the CBKO genotype (Fig. 1b), suggesting that abnormal $\mathrm{Ca}^{2+}$ homeostasis caused by reduced $\mathrm{Ca}^{2+}$ buffering induces ion channel remodeling in the GCs, which, in turn induces hyperexcitability. The increased firing frequency was accompanied by a shortening of the onset time of action potentials (APs; $37.7 \pm 1.8 \mathrm{~ms}, n=8$ for control; 23.9 \pm 
a

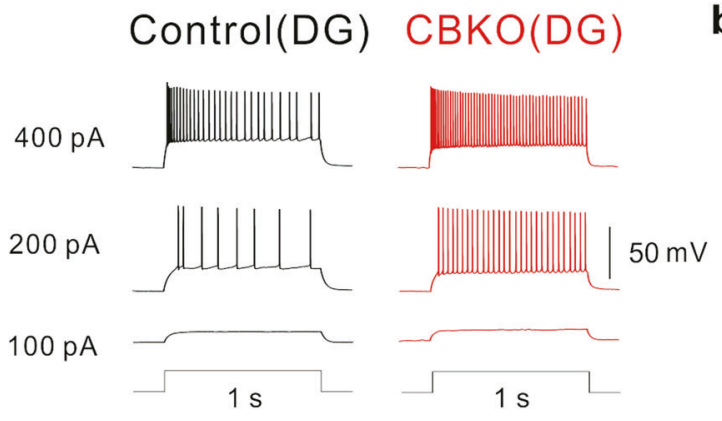

b

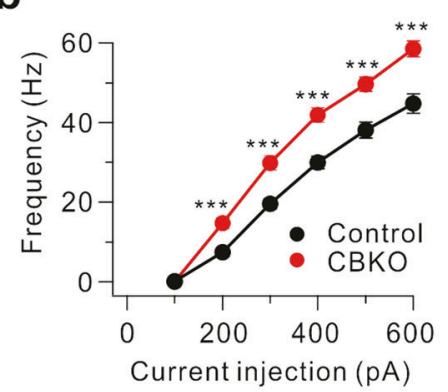

C

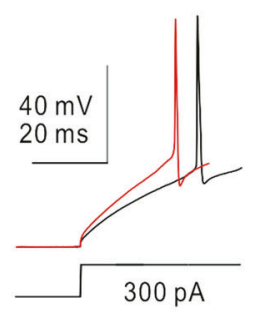

d
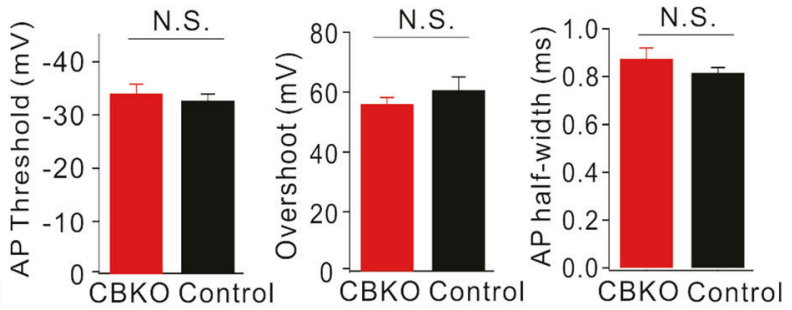

e

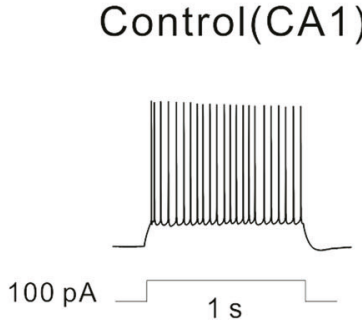

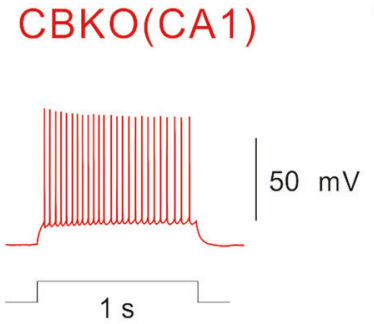

f

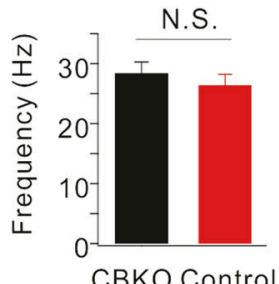

Fig. 1 Increased firing frequency in dentate GCs of CBKO mice. a Trains of APs induced in dentate GCs of control (black) and CBKO mice (red) by $1 \mathrm{~s}$ depolarizing current injections as indicated by numbers left to the traces. $\mathbf{b}$ The F-I curves in the control (black, $n=9$ ) and CBKO (red, $n=8$ ) mice. c Example traces of the first AP elicited by $300 \mathrm{pA}$ current injection from control (black) and CBKO (red) GCs. d Bar graphs showing the onset time, threshold, overshoot amplitude, and half-width of the first AP elicited by 300 pA current injection measured from CBKO (red) and control (black). e Trains of APs induced in CA1 of control (black) and CBKO (red) by 100 pA, 1 s depolarizing current injection. f Bar graph for AP frequency at $100 \mathrm{pA}$ current injection in CA1 cells of control and CBKO mice. Data are represented as the mean \pm SEM. ${ }^{* *} P<0.01$, ${ }^{* * *} P<0.001$, N.S. (not significant) $P>0.05$ by Student's $t$ test.

$3.9 \mathrm{~ms}, n=6$ for CBKO GCs, $P=0.01388$, Fig. 1c, d). The AP threshold and AP shapes, measured by overshoot and half-width, were not affected in the CBKO GCs (Fig. 1d). In contrast, no significant difference was found in CA1 pyramidal neurons between control and CBKO mice (Fig. 1e, f), suggesting that the changes in ion channels that cause hyperexcitability in the CBKO genotype are specific to GCs.

\section{Impaired pattern separation in CBKO mice}

Low excitability of the DG is considered important for information processing in the hippocampus, particularly for pattern separation $^{37}$. We addressed whether the increased firing of GCs in CBKO mice leads to an impairment in pattern separation during the contextual fear discrimination test. We first subjected CBKO mice to contextual fear conditioning using a pair of similar contexts (A and $B$ ). Both had the same metal grid floor, but $B$ had a unique odor ( $1 \%$ acetic acid), dimmer lighting ( $50 \%$ of $A)$, and a $15^{\circ}$ slope on the floor. As shown in Fig. 2a, the mice learned to discern a similar context (Context B) over several days with a single footshock in Context $A$. On the first 3 days, mice were placed only into $A$, receiving a single footshock after $180 \mathrm{~s}$. On days 4 and 5 , the mice of each genotype were divided into two groups. One group of each genotype was exposed to Context $A$ on day 4 and to Context $B$ on day 5 , while the other group was exposed to
Context B on day 4 and to Context A on day 5. No group received a footshock in either context, and freezing was evaluated for $5 \mathrm{~min}$. Both genotypes showed identical freezing kinetics across the 5 min test in Context A (Fig. 2b) and equivalent generalization between contexts (Fig. 2c, two-way ANOVA, genotype: $F_{(1,32)}=$ $0.30, P=0.58$, context: $F_{(1,32)}=1.17, P=0.29$, genotype $\times$ context: $\left.F_{(1,32)}=0.03, P=0.86\right)$. The mice were subsequently trained to discriminate these contexts by visiting the two contexts daily for 8 days in 2-h intervals (from day 6 to 13), always receiving a footshock $180 \mathrm{~s}$ after being placed in Context A but not in Context $B$. The daily discrimination ratio was calculated as the ratio of freezing during the $180 \mathrm{~s}$ in Context $A$ to the total freezing during both visits $(A$ and $B)$. On day 6 , neither genotype could distinguish between contexts (Fig. 2d, e, genotype: $F_{(1,32)}=0.005, P=0.94$, context: $F_{(1,32)}=0.001, P=0.97$, genotype $\times$ context: $F_{(1,32)}=0.32$, $P=0.57)$; thus, the discrimination ratio was $\sim 0.5$. As the experiment progressed, the control mice gained the ability to discriminate Context B from Context A effectively, and the discrimination ratio increased. However, CBKO mice exhibited significant deficits in the acquisition of discrimination ability (Fig. $2 \mathrm{~d}$ ) and showed elevated freezing in the shock-free Context $B$ (Fig. $2 \mathrm{e}, t$ test, Context $\mathrm{B}, P<0.0001$, two-way ANOVA, genotype: $F_{(1,32)}$ $=6.71, P=0.01$, context: $F_{(1,32)}=52.99, P<0.0001$, genotype $\times$ context: $\left.F_{(1,32)}=25.60, \quad P<0.0001\right)$. To examine whether the 
a Pattern separation

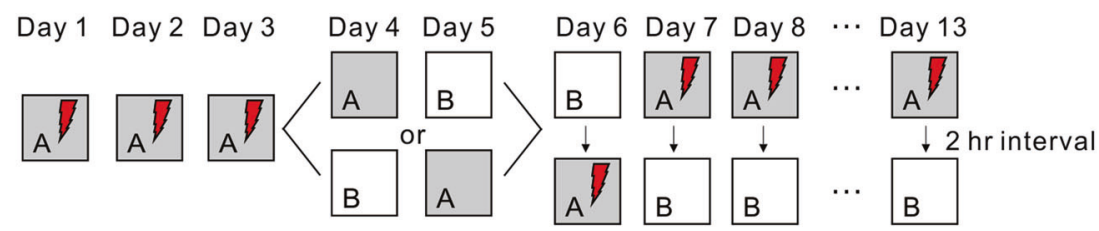

b

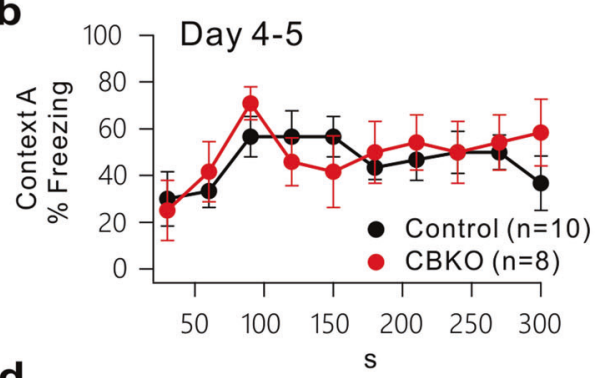

d

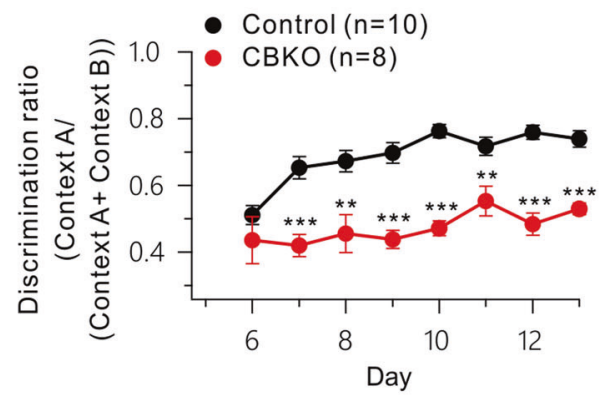

f

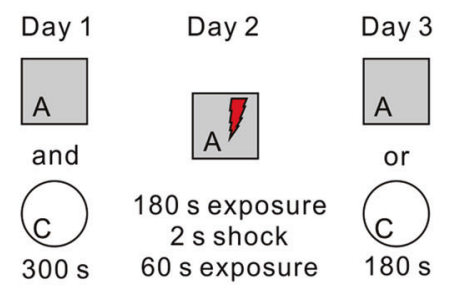

c

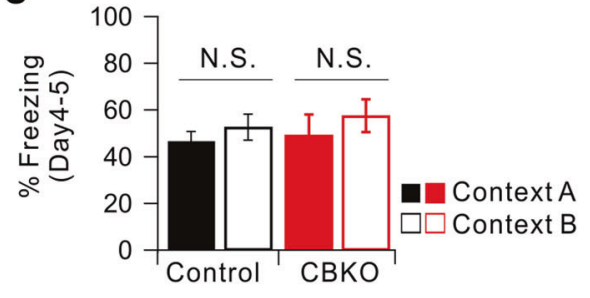

e

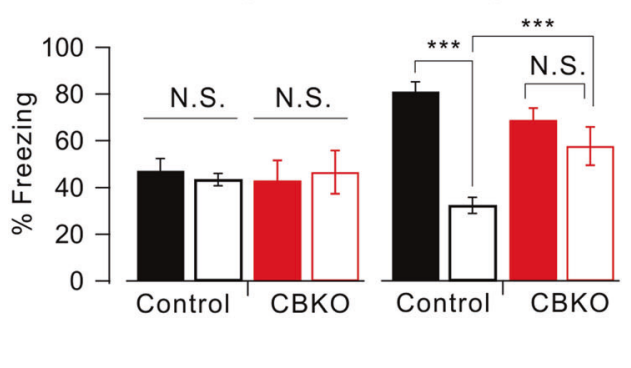

g A (C) $\quad$ anContext A

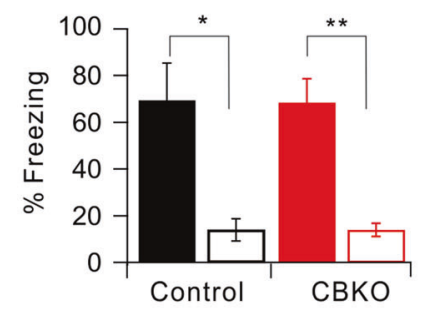

h

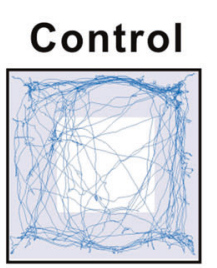

i
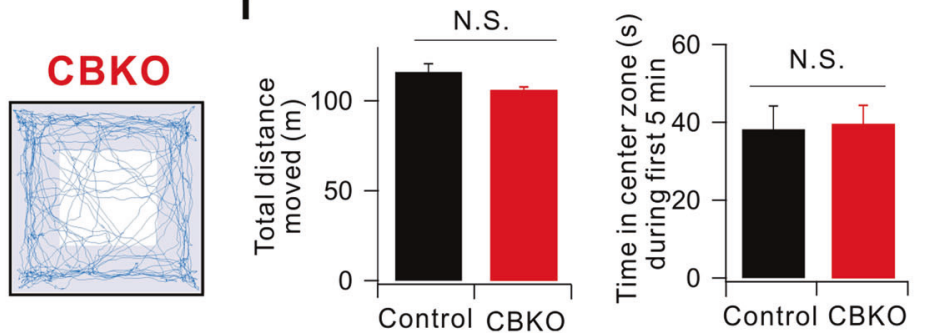

Fig. 2 Impaired pattern separation in CBKO mice. a Experimental procedure for pattern separation in 15- to 19-week-old control ( $n=10$ ) and CBKO $(n=8)$ mice. $\mathbf{b}$ On days 4 and 5 , the kinetics of freezing across the 5 min test in Context A. c The percentage of freezing in Context A (filled bar) and Context B (open bar) on days 4 to 5 in both contexts (A and B). Control (black, $n=10)$ and CBKO (red, $n=8)$ mice displayed equal amounts of freezing in both contexts (A and B). d On days $6-13$, the time course of the discrimination ratio in control (black, $n=10)$ and CBKO (red, $n=8$ ) mice. e The percentage of freezing in Context A (filled bar) and Context B (open bar) for the control (black, $n=10$ ) and CBKO (red, $n=8$ ) mice on day 6 (left) and day 11 (right). $\mathbf{f}$ Experimental procedure for one-trial contextual fear conditioning between control ( $n=8$ ) and CBKO $(n=8)$ mice. $g$ The percentage of freezing in Context A (filled bar) and context C (open bar, distinct object) for the control $(n=8)$ and CBKO $(n=8)$ mice. $\mathbf{h}$ The trajectories traveled by the control (left) and CBKO (right) mice in the open-field test showed how the mice traveled. i Summary bar graph of the total traveled distance (left) and time in the center zone during the first 5 min (right). Total distance moved $(\mathrm{m})$, Control, $n=6,116.20 \pm 4.45, \mathrm{CBKO}, n=6,106.11 \pm 1.79, P=0.06175$; Time in the center zone (sec), Control, $n=6,11.81 \pm 1.22$, CBKO, $n=6,13.91 \pm 1.55, P=0.31208$. Data are represented as the mean \pm SEM. 

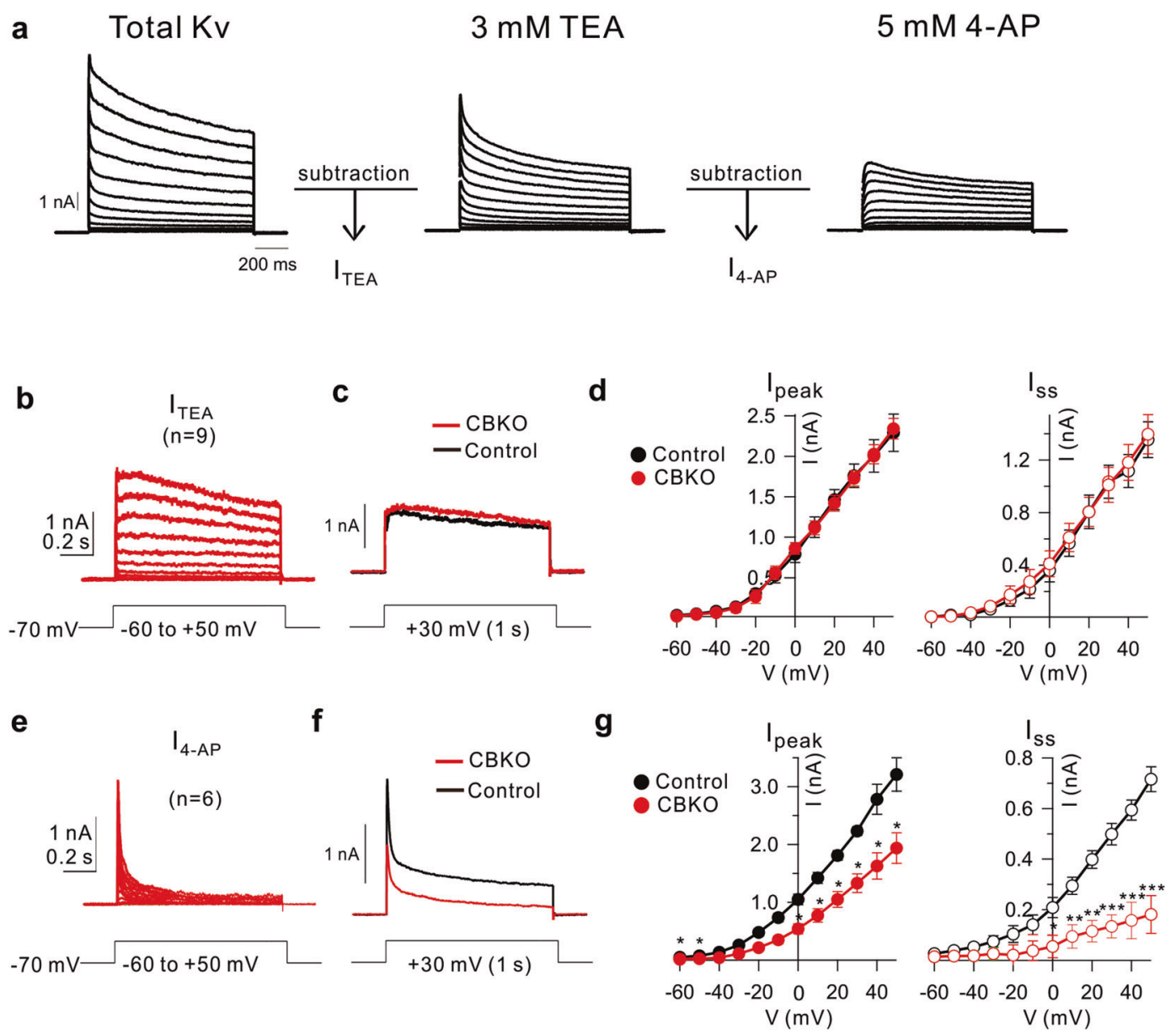

Fig. 3 Decrease 4-AP-sensitive current in CBKO GCs. a Representative whole-cell voltage-gated $\mathrm{K}^{+}$currents from control dentate GCs. Currents were evoked in response to $1 \mathrm{~s}, 10 \mathrm{mV}$ voltage steps to potentials between -60 and $+50 \mathrm{mV}$ from a holding potential of $-70 \mathrm{mV}$. After recording the total outward currents, we changed the bath solution, which contained 3 mM TEA, and the difference currents before and after TEA were measured to obtain TEA-sensitive currents $\left(I_{\text {TEA }}\right)$. Subsequently, $5 \mathrm{mM}$ 4-AP was added to obtain 4-AP-sensitive currents (I 4 -AP). b $\mathrm{I}_{\text {TEA }}$ obtained from CBKO GCs $(n=9)$ were averaged. c Superimposed I IFA traces at $+30 \mathrm{mV}$ measured CBKO (red) and control (black) at $+30 \mathrm{mV}$. d Amplitudes of the peak currents $\left(\mathrm{I}_{\text {peak }}\right)$ and steady-state currents $\left(\mathrm{I}_{\mathrm{SS}}\right)$ for $\mathrm{I}_{\text {TEA }}$ are plotted as a function of the given potential $(\mathrm{V})$. Control (black closed circle, $n=4)$ and CBKO (red closed square, $n=9$ ). e The difference currents before and after applying $5 \mathrm{mM} 4$-AP. f Superimposed $\mathrm{I}_{4-\mathrm{AP}}$ traces measured from CBKO (red) and the control (black) at $+30 \mathrm{mV}$. $\mathrm{g} \mathrm{I}_{\text {peak }}$ and $\mathrm{I}_{\mathrm{ss}}$ for $5 \mathrm{mM} \mathrm{4-AP-sensitive} \mathrm{I}_{\mathrm{A}}$ currents, as shown in Fig. $3 \mathrm{~d}$. Control (black closed circle, $n=9$ ) and CBKO (red closed circle, $n=6$ ). Data are represented as the mean \pm SEM. ${ }^{*} P<0.05,{ }^{*} P$ $<0.01,{ }^{* * *} P<0.001$, N.S. not significant $(P>0.05)$ by Student's $t$ test.

impaired discrimination between similar contexts in CBKO mice was due to a problem with memory acquisition, we examined the context specificity of the conditioning by assessing freezing behavior using a distinct pair of contexts ( $A$ and $C$ ). This distinct context (context $C$ ) evoked significantly lower levels of freezing (similar in the two genotypes) than Context $A$ (Fig. 2f, g, genotype: $F_{(1,11)}=0.002, P=0.96$, context: $F_{(1,11)}=30.34, P<0.0001$, genotype $\times$ context: $\left.F_{(1,11)}=0.002, P=0.96\right)$. These data imply that CBKO mice have no deficit in learning or discriminating between very distinct contexts but have difficulty discriminating between similar contexts (pattern separation). We also tested the locomotor activity and anxiety levels of CBKO mice using the open-field test. Control and CBKO mice showed similar exploratory patterns, as they moved the same distance in the open-field box and spent a similar amount of time in the center zone (Fig. $2 \mathrm{~h}, \mathrm{i}$ ).

\section{A reduced Kv4.1 current underlies increased excitability in CBKO GCs}

We then investigated the ion channel mechanisms responsible for the hyperexcitability of CBKO GCs. Since the increased firing was not associated with a change in the AP threshold, the involvement of $\mathrm{Na}^{+}$channels was unlikely. Therefore, we analyzed the difference in $\mathrm{K}^{+}$currents between $\mathrm{CBKO}$ and control CGs. Whole-cell $\mathrm{K}^{+}$currents were recorded in voltage-clamp mode by applying depolarizing voltage steps from -60 to $+50 \mathrm{mV}$ (in $10 \mathrm{mV}$ increments, $1 \mathrm{~s}$ duration) from a holding potential of $-70 \mathrm{mV}$. TTX, $\mathrm{Cd}^{2+} / \mathrm{Ni}^{2+}$, bicuculline, and CNQX were added to the external solution to block $\mathrm{Na}^{+}$channels, $\mathrm{Ca}^{2+}$ channels, $\mathrm{GABA}_{\mathrm{A}}$

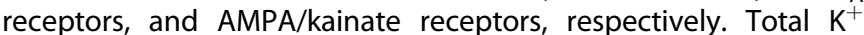
currents were dissected into TEA-sensitive (ITEA) and 4-AP-sensitive $\mathrm{K}^{+}$currents $\left(\mathrm{I}_{4-\mathrm{AP}}\right)$ (Fig. 3a). The $\mathrm{I}_{\text {TEA }}$ obtained from CBKO GCs $(n=$ 9) showed no significant difference from that of control GCs, as reported previously ${ }^{25}$; both the peak $\left(\mathrm{I}_{\text {peak }}\right.$ at $+30 \mathrm{mV} ; 1.807 \pm$ $0.152 \mathrm{nA}, n=9$, for control; $1.727 \pm 0.096 \mathrm{nA}, n=9$, for CBKO, $P=$ $0.66)$ and steady-state currents $\left(I_{s s}\right.$ at $+30 \mathrm{mV} ; 1.107 \pm 0.126 \mathrm{nA}, n$ $=9$, for control: $1.012 \pm 0.133 \mathrm{nA}, n=9$, for CBKO, $P=0.609$ ) were comparable between genotypes (Fig. $3 b-d$ ). In contrast, the characteristics of $\mathrm{I}_{4-\mathrm{AP}}$ in CBKO GCs were different from those in control GCs. The inactivation phase of $\mathrm{I}_{4-\mathrm{AP}}$ in $\mathrm{CBKO}$ GCs showed a fast time constant with little $I_{s s}$ (Fig. 3e), which are typical characteristics of A-type $\mathrm{K}^{+}$currents, while that in the control GCs had a significant proportion of $\mathrm{I}_{\mathrm{ss}}$, which is attributable to Kv4.1 currents (Fig. $3 f)^{25}$. The amplitude of $\mathrm{I}_{4-\mathrm{AP}}$ in CBKO GCs was significantly smaller than that in the control GCs (Fig. 3g). The 
a

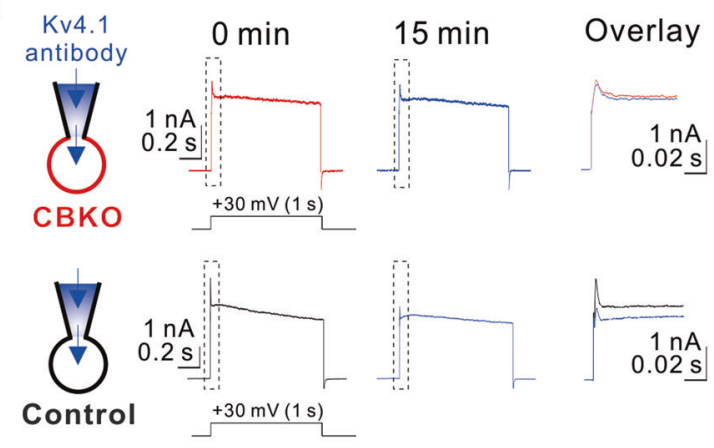

C

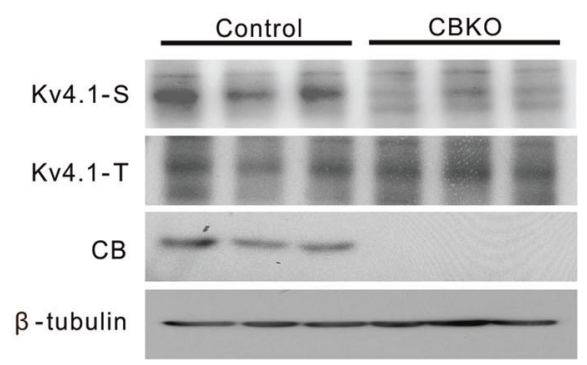

b

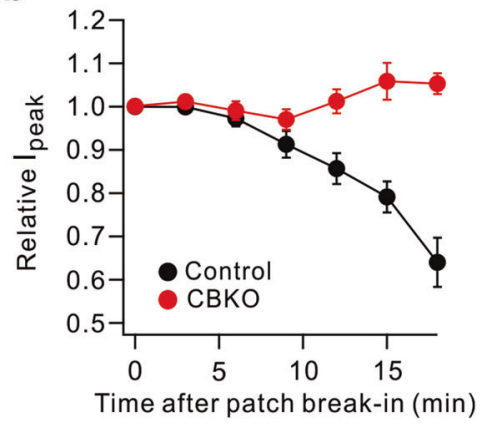

d

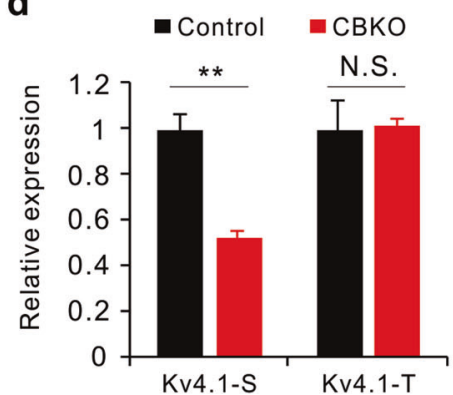

Fig. 4 Evidence for the reduced Kv4.1 currents in CBKO GCs. a Top: whole-cell, voltage-gated K currents activated by $+30 \mathrm{mV}$ depolarizing pulses in CBKO GCs with intracellular solution containing Kv4.1 antibodies, recorded shortly after rupture (0 min) and after full diffusion (15 min). Each trace is expanded and superimposed for comparison (dashed box). Bottom: same as described at (top) but in control GCs. b Time course of normalized $I_{\text {peak }}$ at each time point after break-in. c Western blot analysis of total Kv4.1 (Kv4.1-T) and surface Kv4.1 (Kv4.1-S) in the DG of 8-week-old control and CBKO mice. The absence of calbindin (CB) expression was confirmed in the DG of CBKO mice. $\beta$-Tubulin was used as a loading control. d Relative protein levels of Kv4.1 in surface or total lysates in CBKO cells compared to control cells. Values are means of three determinants \pm SD. $(n=3)$. ${ }^{* *} P<0.01$, N.S. not significant by Student's $t$ test.

reduction in $\mathrm{I}_{\mathrm{sS}}(63 \%)$ was more pronounced than the reduction in $I_{\text {peak }}(36 \%) . I_{4-A P}$ in CBKO GCs was similar to $I_{4-A P}$ in the control GCs in the presence of anti-Kv4.1 antibodies, as reported previously ${ }^{25}$. This suggests that the outward $\mathrm{K}^{+}$current component reduced in the CBKO GCs is likely to be the Kv4.1 current.

\section{Calbindin regulates the cell-surface localization of Kv4.1 via CaMKII-mediated phosphorylation}

To further confirm that the $\mathrm{K}^{+}$current component reduced in CBKO GCs is the Kv4.1 current, we monitored changes in the outward current amplitude during perfusion of anti-Kv4.1 antibodies through a patch pipette after patch break-in. Anti$\mathrm{Kv} 4.1$ antibodies significantly reduced the outward $\mathrm{K}^{+}$currents in the GCs of control mice but did not induce changes in CBKO GCs (Fig. 4a, b), suggesting that Kv4.1 is not functional in CBKO GCs.

To investigate the mechanism of reduced Kv4.1 current in CBKO GCs, we first tested alterations in Kv4.1 protein expression and surface localization. To monitor membrane localization, isolated DG was labeled with biotin, lysed, and subjected to pulldown with streptavidin beads. Immunoblot analysis revealed that the level of surface-resident Kv4.1 (Kv4.1-S) was significantly reduced in the CBKO DG, while the level of total Kv4.1 protein (Kv4.1-T) was not significantly altered relative to the control DG (Fig. 4c, d). These results suggest that the reduced Kv4.1 current in CBKO GCs is attributable to the impairment of Kv4.1 trafficking to the membrane surface.

To further understand the mechanism underlying changes in Kv4.1 trafficking by reduced $C B$, we infected the mouse hippocampal neuronal cell line HT22 with lentiviruses expressing either a control scrambled RNA or CB-shRNA and examined the surface expression of Kv4.1 in differentiated cells. Similar to the results obtained with the
CBKO DG, the level of membrane-resident Kv4.1 protein was specifically reduced in CB-depleted $\mathrm{HT} 22$ cells without any reduction in the total Kv4.1 level (Fig. 5a). We then examined the level of active phosphorylated CaMKIla ( $p$-CaMKIla), which acts as the main player in the $\mathrm{Ca}^{2+}$ signaling pathway implicated in diverse cellular processes, including the control of neuronal excitability ${ }^{38}$. The level of p-CaMKIla was substantially reduced in CB-depleted HT22 cells (Fig. 5a). Conversely, CB overexpression enhanced the levels of surface Kv4.1 and p-CaMKIla relative to those of the control group (Fig. 5b). These data suggest that CaMKIla might be a downstream effector of CB to control Kv4.1 surface localization, likely through phosphorylation. Thus, we investigated the potential phosphorylation of Kv4.1 in relation to CB levels and CaMKII activities. HEK293T cells were transfected with the expression vectors for Kv4.1-GFP with or without CB, and 2 days later, the cells were treated with the CaMKII inhibitor KN-93 or the relevant control compound $\mathrm{KN}-92$ for $24 \mathrm{~h}$. To monitor the level of phosphorylated Kv4.1, cell lysates were subjected to immunoprecipitation with antiphosphoserine antibodies and immunoblotting analysis. Coexpression of CB and Kv4.1 significantly elevated the phosphorylated Kv4.1 protein level in cells treated with the control compound KN-92, and this effect was abrogated by KN-93 treatment (Fig. 5c, d). These data suggest that $\mathrm{CB}$ facilitates the CaMKII-mediated phosphorylation of Kv4.1, thereby increasing its cell-surface expression in DG and hippocampal cells.

Since the $\mathrm{Ca}^{2+}$ buffering capacity of CBKO GCs is only half that of control $\mathrm{GCs}^{3}$, the intracellular $\mathrm{Ca}^{2+}$ concentration is expected to be higher in CBKO GCs (CBKO GCs are subject to $\mathrm{Ca}^{2+}$ overload). Thus, it appears to be paradoxical that CaMKII inhibition shows a phenotype similar to that of CBKO. To understand how p-CaMKII is downregulated by CB knockdown, we analyzed the effect of a 
a

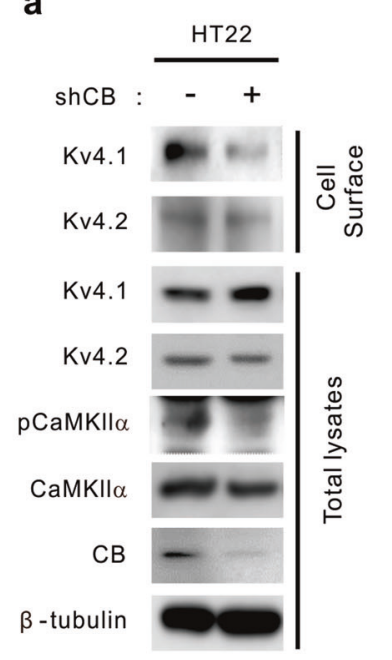

b

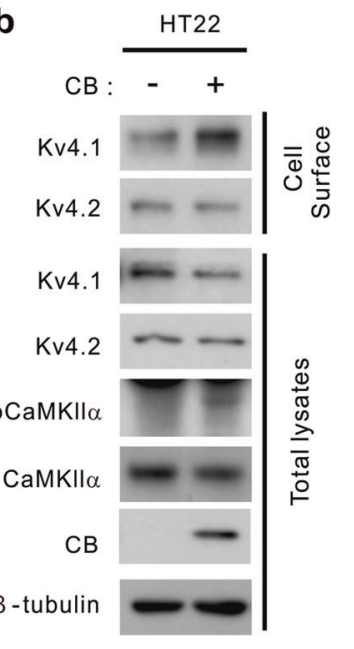

C

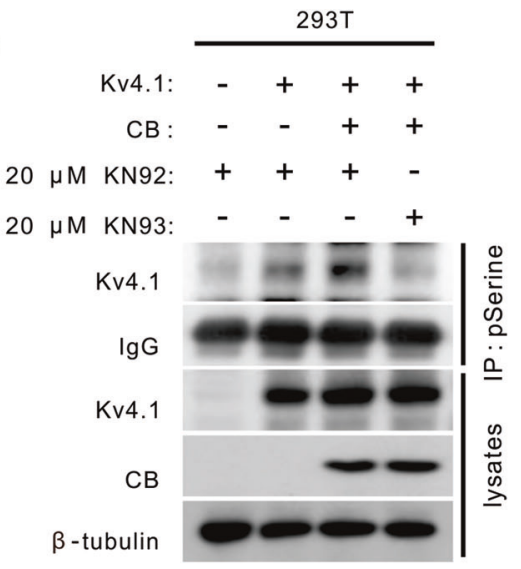

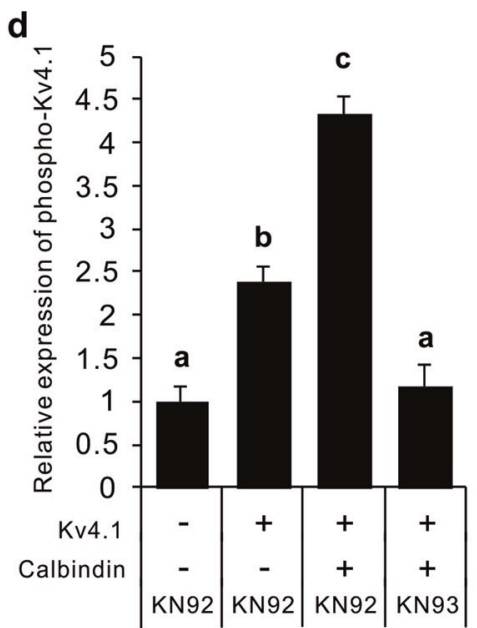

e

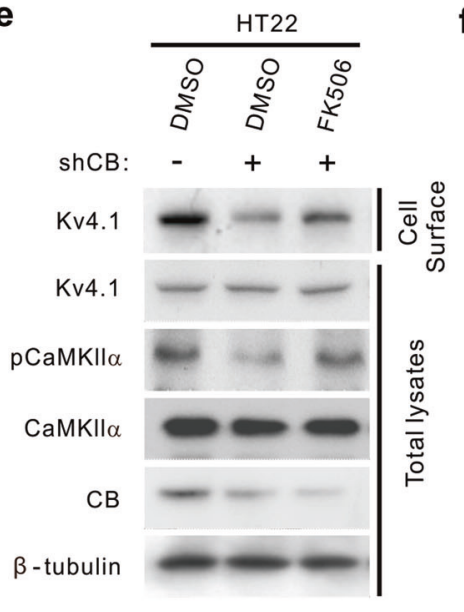

f

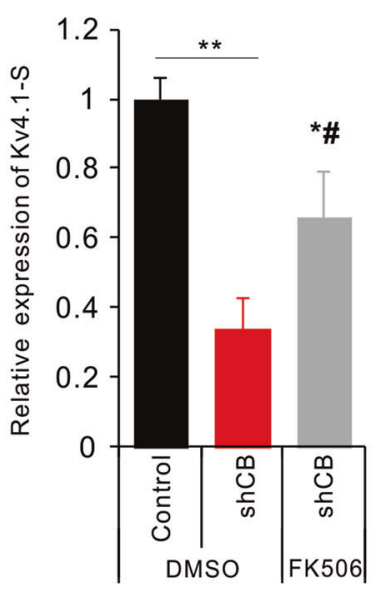

Fig. 5 Calbindin regulates the cell-surface localization of Kv4.1 via CaMKII-mediated phosphorylation. a, b Cell-surface biotinylation assay of control and shRNA calbindin (a) or calbindin (b)-transfected HT22 cells followed by immunoblot analysis with the indicated antibodies. c Analysis of serine phosphorylation of Kv4.1 in 293T cells expressing control or Kv4.1 and calbindin treated with $20 \mu \mathrm{M}$ KN-92 or KN-93 for $24 \mathrm{~h}$. d Quantification of the relative phosphorylation levels of Kv4.1 at serine residues shown in (c). The intensities were normalized to the level of $\beta$-tubulin. Values are means of triplicate determinants (ANOVA Tukey). Letters indicate statistically distinct groups $(P<0.05)$. e Surface biotinylation assay of control and calbindin-depleted HT22 cells treated with vehicle or $10 \mu \mathrm{M} \mathrm{FK506} \mathrm{for} 1 \mathrm{~h}$ followed by immunoblot analysis with the indicated antibodies. $\mathbf{f}$ Quantification of the relative cell-surface protein levels of Kv4.1 shown in (e). The intensities were normalized to the level of $\beta$-tubulin. ${ }^{*} P<0.05,{ }^{* *} P<0.01$ versus the control group; ${ }^{*} P<0.05$ versus the shCB group.

$\mathrm{Ca}^{2+}$-dependent phosphatase inhibitor, FK506, on p-CaMKII and the surface localization of Kv4.1 in CB-depleted HT22 cells (Fig. 5e, f). $C B$ depletion reduced the level of surface Kv4.1 protein after treatment with the vehicle dimethyl sulfoxide (DMSO), while FK506 treatment significantly restored the surface Kv4.1 levels (Fig. 5e, f). These results suggest that $C B$ knockdown may activate $\mathrm{Ca}^{2+}$-dependent phosphatase, which, in turn, decreases $\mathrm{p}$-CaMKII levels and Kv4.1 surface localization.

\section{Blockade of CaMKII induces hyperexcitability in GCs}

To confirm whether CaMKII-dependent phosphorylation is a key mechanism for Kv4.1 activity in GCs, we examined the effect of a CaMKII inhibitor (KN-93) on outward $\mathrm{K}^{+}$currents (Fig. 6a). In control GCs, outward $\mathrm{K}^{+}$currents were reduced significantly by $\mathrm{KN}-93(625.6 \pm 160.9 \mathrm{pA}$ at $+30 \mathrm{mV}, n=7)$, which was comparable to the previously reported Kv4.1 current amplitude in control GCs $(619.6 \pm 66.4 \mathrm{pA})^{25}$. In contrast, $\mathrm{KN}-93$ did not show a significant effect in CBKO GCs (Fig. 6b, c), which was consistent with the idea that the CaMKII-dependent Kv4.1 current is absent in CBKO GCs. Accordingly, GCs pretreated with CaMKII inhibitors displayed hyperexcitability, which was comparable to that of CBKO GCs (Fig. $6 \mathrm{~d}, \mathrm{e})$. These results support the idea that the same outward $\mathrm{K}^{+}$ current component decreased by CaMKII inhibitors is also reduced in CBKO GCs.

\section{CaMKII regulates Kv4.1 activity by phosphorylating S555 of Kv4.1}

A sequence analysis to predict the phosphorylation sites in Kv4.1 by CaMKII using the Phosphosite database revealed three potentially phosphorylated serine residues at positions 265,555 , and 568 of Kv4.1 (Fig. 7a). Thus, we generated serine-to-alanine mutants for these sites in Kv4.1 and analyzed the phosphorylation status by CaMKII activity. Co-transfection with Kv4.1 and CaMKIla elevated Kv4.1 levels immunoprecipitated with anti-phosphoserine antibody compared to the Kv4.1 single-expression control (Fig. 7b, c). The phosphorylation levels of R265A and S568A mutants were equivalent to wild-type Kv4.1 in response to CaMKIla. In contrast, the S555A mutant failed to show any increase in response to CaMKIla, suggesting that S555 is a target phosphorylation site for CaMKIla. 
a
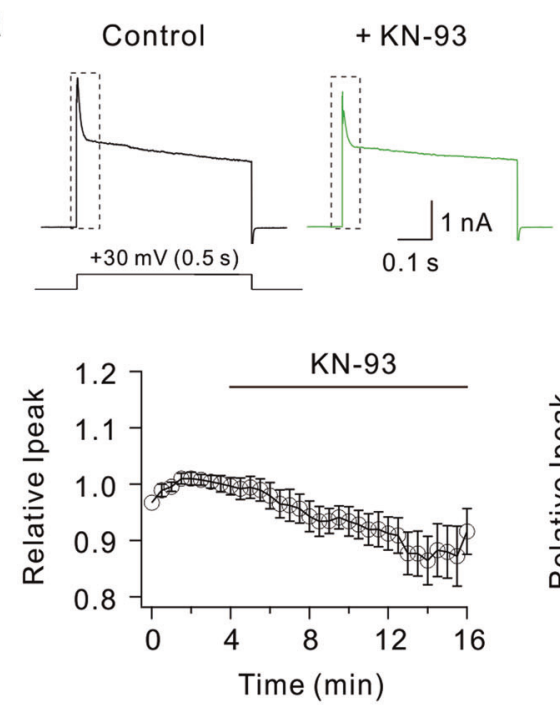

d

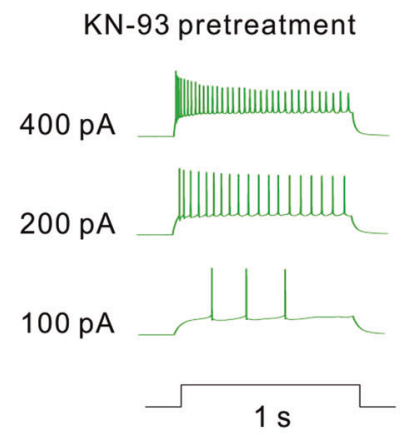

b

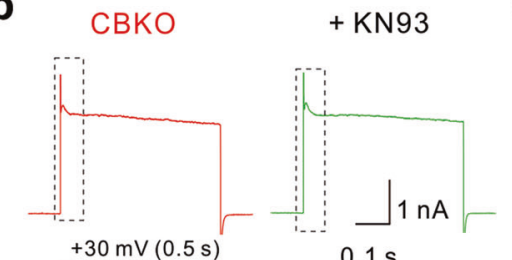

$+30 \mathrm{mV}(0.5 \mathrm{~s})$

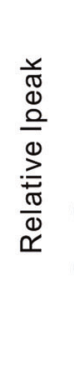

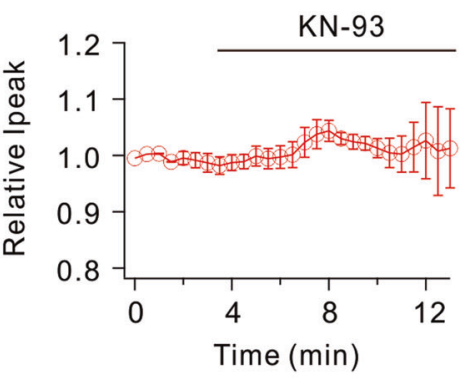

e

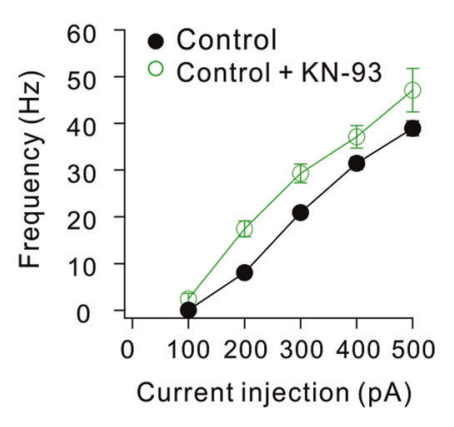

C
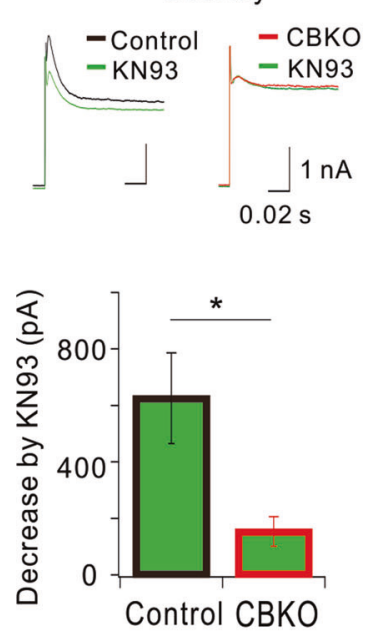

Fig. $6 \mathrm{KN}-93$ decreases $\mathrm{K}^{+}$currents in control GCs but not in CBKO GCs. a Representative whole-cell $\mathrm{K}^{+}$currents at $+30 \mathrm{mV}$ in control GCs before (black) and after KN-93 application (green). Changes in $\mathrm{K}^{+}$current amplitude after KN-93 application were averaged from seven cells, and the mean \pm SEM was plotted (lower panel). b Representative whole-cell $\mathrm{K}^{+}$currents at $+30 \mathrm{mV}$ in CBKO GCs before (red) and after KN-93 application (green). Changes in $\mathrm{K}^{+}$current amplitude after $\mathrm{KN}-93$ application were averaged from seven cells, and the mean $\pm \mathrm{SEM}$ was plotted (lower panel). c Representative whole-cell $\mathrm{K}^{+}$currents at $+30 \mathrm{mV}$ shown in $(\mathbf{a}, \mathbf{b})$ with dotted boxes are overlaid on an expanded time scale. Bar graphs indicate decreases in $\mathrm{I}_{\text {peak }}$ by KN-93 (lower panel). Mean \pm SEM. d Representative AP traces induced by injecting depolarizing currents as indicated by the number left to the traces in control GCs pretreated with KN-93 (left) and the corresponding F-l curve (green circles, right). The F-I curve from control GCs shown in Fig. $1 \mathrm{~b}$ was superimposed for comparison (black line). e The firing frequency obtained by $200 \mathrm{pA}$ current injection obtained in the presence of KN-93 in control GCs (green, $n=7$ ) was compared with that in the control (black), as shown in Fig. 1 b. Data are represented as the mean \pm SEM. ${ }^{* *} P<0.001$. N.S. not significant by Student's $t$ test.

We further examined the correlation between CaMKII-induced phosphorylation and Kv4.1 channel function by recording wholecell currents in HEK293T cells expressing WT or S555A Kv4.1 (Fig. $7 d$, e). Compared to WT, S555A Kv4.1 exhibited remarkably decreased currents. The current density at $+50 \mathrm{mV}$ was $473.58 \pm$ $32.3 \mathrm{pA} / \mathrm{pF}(n=4)$ for WT Kv4.1, and it decreased to $254.86 \pm$ $49.34 \mathrm{pA} / \mathrm{pF} \quad(n=5 ; \quad P<0.05)$ for S555A Kv4.1. Furthermore, CaMKIla inhibition with KN-93 decreased WT Kv4.1 activity to $350.36 \pm 10.57 \mathrm{pA} / \mathrm{pF}(n=4, P<0.05$ vs. WT Kv4.1 under control conditions), while it did not further reduce S555A Kv4.1 activity $(180.92 \pm 34.71 \mathrm{pA} / \mathrm{pF}, \quad n=5 ; P>0.05$ vs. S555A Kv4.1 under control conditions). The S555A mutation and KN-93 treatment did not change the inactivation kinetics (Fig. 7f). These data suggest that the phosphorylation of the S555 residue in Kv4.1 by CaMKII is a key regulatory step in Kv4.1 activity.

\section{The functional deficit in calcium buffering in Tg2576 GCs is restored by antioxidant treatment}

Neuronal depletion of $C B$ was reported to be tightly linked to ADrelated cognitive deficits. However, this depletion was observed in $A D$ model mice aged at least 6 months ${ }^{8}$. We recently reported that
Kv4.1 is downregulated, leading to hyperexcitability in dentate GCs in 1-2-month-old Tg2576 mice ${ }^{39}$. Therefore, we asked whether dysfunctional $\mathrm{Ca}^{2+}$ buffering has pathophysiological significance in early preclinical stages. To this end, we measured the cellular $\mathrm{Ca}^{2+}$ buffering capacity in mature GCs from 1- to 2month-old WT and Tg2576 mice using a method described in our previous paper ${ }^{3}$. To estimate $\mathrm{K}_{\mathrm{E}}$ (the sum of the $\mathrm{Ca}^{2+}$ binding ratio of mobile and static endogenous $\mathrm{Ca}^{2+}$ buffers), we loaded GCs with fura-2 $(250 \mu \mathrm{M})$ using whole-cell patch pipettes $\left(R_{S}=20.5 \pm\right.$ $1.0 \mathrm{M} \Omega$ ), and evoked $\mathrm{Ca}^{2+}$ transients (CaTs) by applying voltage pulses (from -70 to $0 \mathrm{mV}, 40 \mathrm{~ms}$ duration) at different time points during fura-2 loading (Fig. 8a). As the cytosolic fura-2 concentration increased gradually after patch break-in, CaTs exhibited decreased amplitudes $(A)$ and increased decay time constants $(\tau)$. To estimate the $\kappa_{E}$ value, we plotted $\tau$ against $K_{B}$ and obtained the $x$-intercept from the extrapolation of the linear fit (Fig. 8b). The mean $K_{E}$ value in WT GCs estimated from the $\tau$ vs $K_{B}$ plots was $340.7 \pm 12.5(n=10)$, while that in $\mathrm{Tg} 2576 \mathrm{GCs}$ was $206.8 \pm 4.7$ ( $n$ $=7)$, which was significantly lower than that in WT GCS $(P=$ 0.00000034 , Fig. 8C). The mean $K_{E}$ values estimated from the $A^{-1}$ vs $K_{B}$ plots showed similar results (WT GCs: $342.4 \pm 15.4, n=10$, 
a

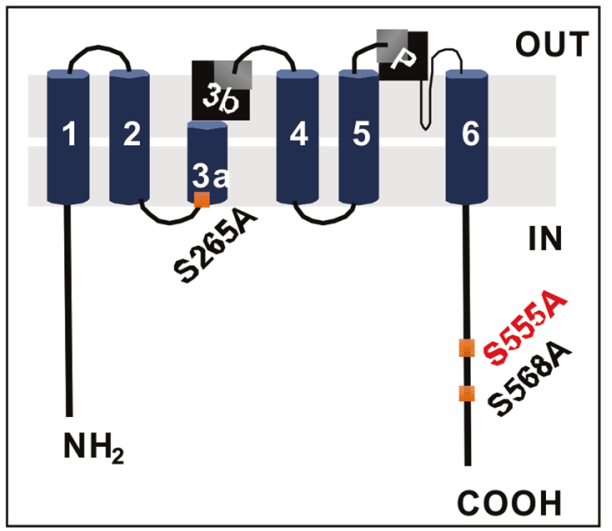

b

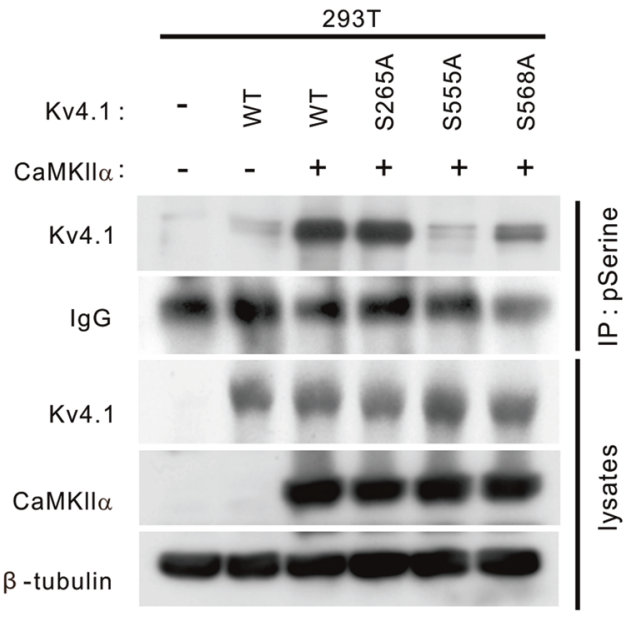

d

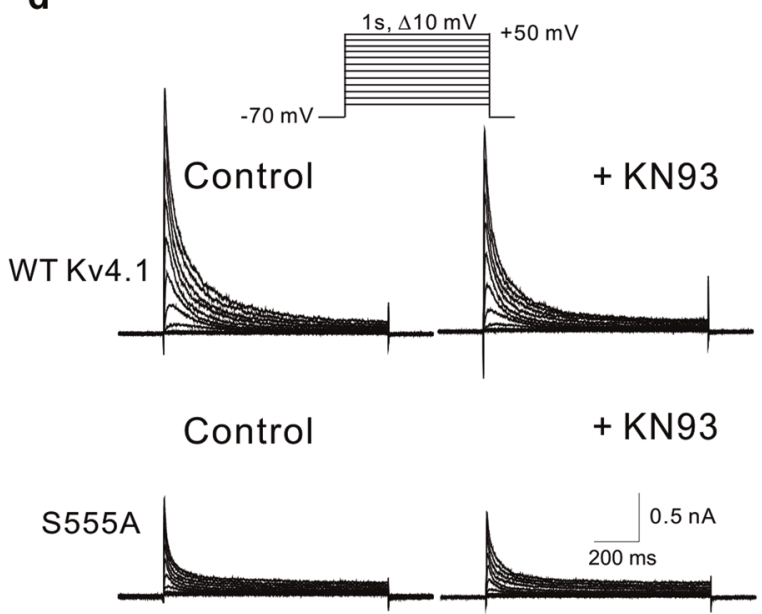

C

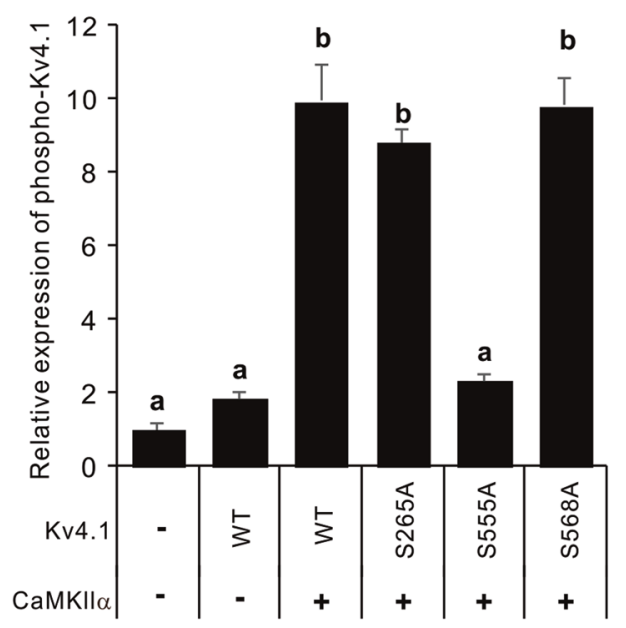

e
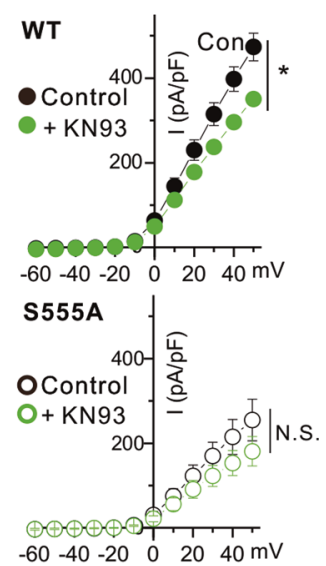

e
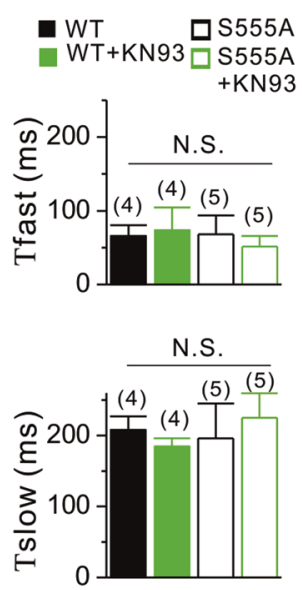

KCND1 WT: RFLRSVMSLIDVVAI

KCND1 S265A: RFLRSVMALIDVVAI

KCND1 WT: TASVSRGSMQELDTL

KCND1 S555A: TASVSRGAMQELDTL

KCND1 WT: TLAGLRRSPAPQTRS

KCND1 S568A: TLAGLRRAPAPQTRS

Fig. 7 CaMKII regulates Kv4.1 activities by phosphorylating S555 of Kv4.1. a Schematic representation of the domain structure of Kv4.1. Potential serine phosphorylation sites are labeled red. (left) Alignments of the potential serine phosphorylation site are shown in red, and serine residues $(S)$ are switched to alanine (A). b Immunoprecipitation with anti-phospho-serine antibody and immunoblotting with the indicated antibodies in 293T cells expressing control, WT Kv4.1, or mutant Kv4.1 (S265A, S555A, and S568A) with CaMKIl. c Quantification of serine phosphorylation levels of Kv4.1. Values are the means of triplicate determinants (ANOVA Tukey, $P<0.05$ ). Letters indicate statistically distinct groups. d Representative current recordings from HEK293T cells expressing WT Kv4.1 (upper) or S555A Kv4.1 (lower) before and after $\mathrm{KN}-93(1 \mu \mathrm{M})$ treatment for $5 \mathrm{~min}$. Currents were elicited by voltage steps from -60 to $+50 \mathrm{mV}$ at a holding potential of $-70 \mathrm{mV}$. e Current-voltage curves for peak current amplitude of WT and S555A Kv4.1 currents in the absence and presence of KN-93 (1 $\mu \mathrm{M})$. Data represent mean \pm SEM. ${ }^{*} P<0.05$, Paired Student's $t$ test. $\mathbf{f}$ The effect of S555A mutation and KN-93 on the fast and slow inactivation time course. The inactivation time course of Kv4.1 currents was well fitted with a double exponential function. Data are represented as the mean \pm SEM. N.S. not significant by Student's $t$ test. 
a
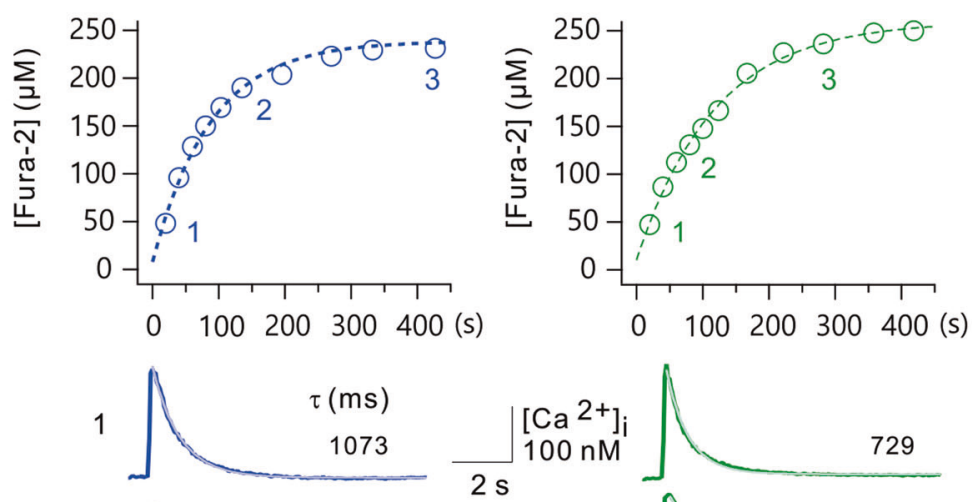

2

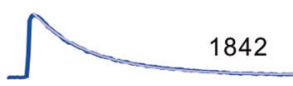

$\left.{ }_{100}^{\left[\mathrm{Ca}{ }^{2+}\right.}\right]_{\mathrm{i}}$

3

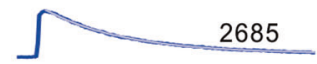

$\begin{array}{llll}100 & 200300400(\mathrm{~s})\end{array}$

$\operatorname{Tg} 2576$

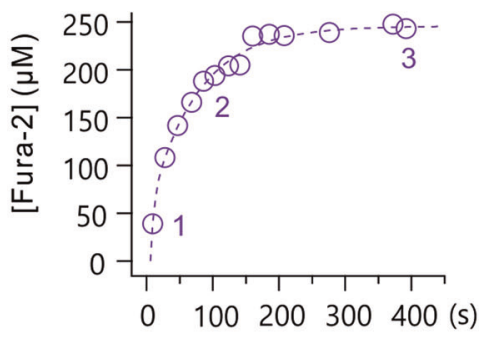

29
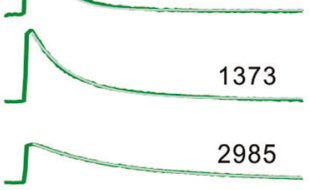

Tg2576 + Trolox

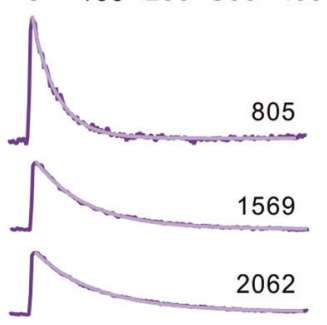

b

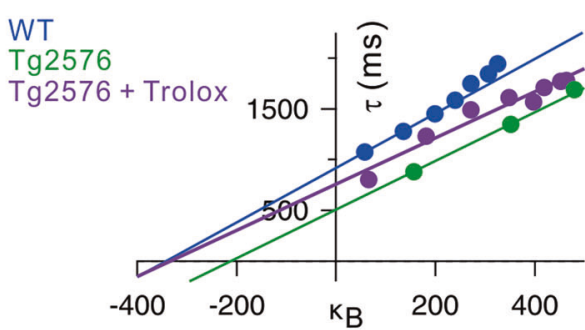

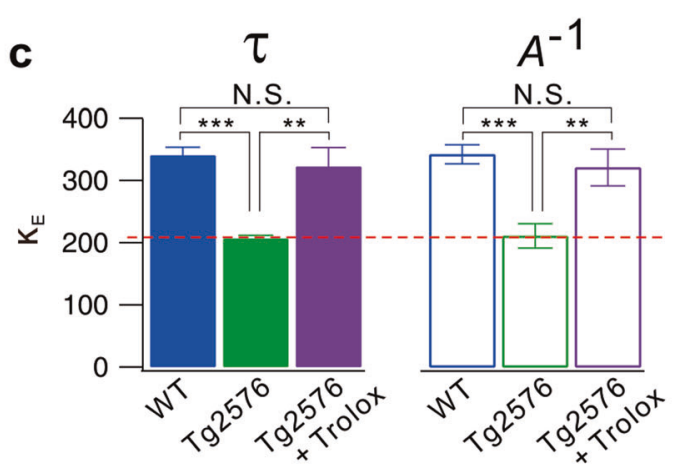

d

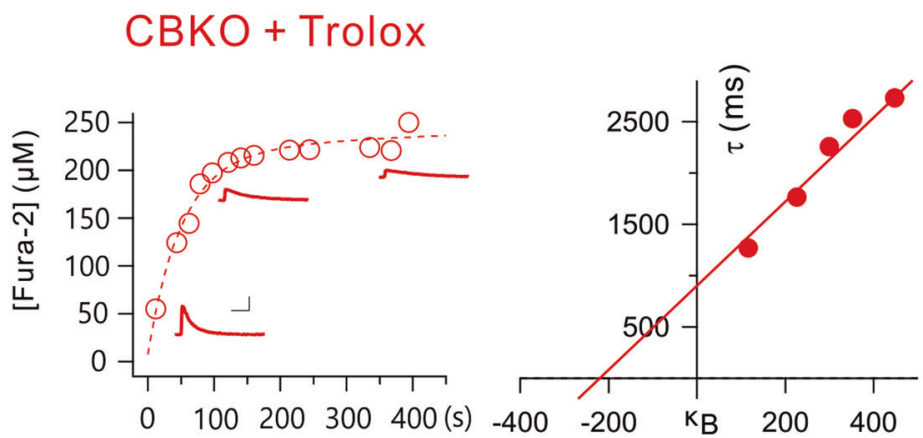

e

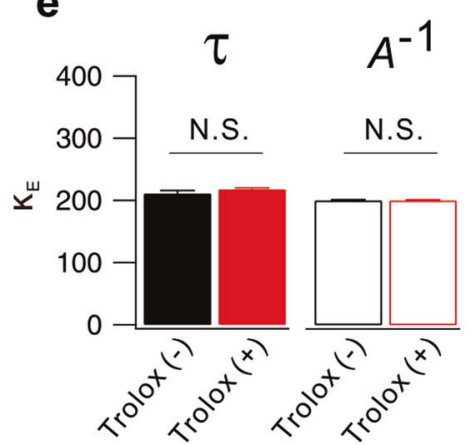

Fig. 8 Endogenous $\mathrm{Ca}^{2+}$ binding ratios $\left(\mathrm{K}_{\mathrm{E}}\right)$ are reduced in dentate $\mathrm{GCs}$ of Tg2576 GCs. a Time course of fura-2 loading (250 $\left.\mu \mathrm{M}\right)$ during whole-cell patch recording in wild-type (WT, blue), Tg2576 (green), and Tg2576 slices pretreated with Trolox (500 $\mu$ M, violet) for 1 hr. Ca ${ }^{2+}$ transients (CaTs) were evoked by a depolarizing pulse (from -70 to $0 \mathrm{mV}, 40 \mathrm{~ms}$ in duration). Fura-2 concentrations were calculated from isosbestic fluorescence and plotted as a function of whole-cell recording time. Exemplary CaTs shown underneath the loading curve were obtained at 20,135, and $427 \mathrm{~s}$ in WT, 40, 124, and $282 \mathrm{~s}$ in Tg2576, and 9, 103, and $392 \mathrm{~s}$ in Tg2576 + Trolox. Inset scale bars indicate $100 \mathrm{nM}$ $\left[\mathrm{Ca}^{2+}\right]_{i}$ and $2 \mathrm{~s}$. b Plots of time constants $(\tau)$ for the decay phases of CaTs as a function of incremental Ca ${ }^{2+}$ binding ratios of fura-2 ( $\left.\kappa_{\mathrm{B}}\right)$. An $x-$ intercept of the linear fit to this plot was considered the endogenous $\mathrm{Ca}^{2+}$ binding ratio $\left(\kappa_{\mathrm{E}}\right)$. c Mean values for $\kappa_{\mathrm{E}}$ from WT (blue, $n=10$ ), Tg2576 (green, $n=7$ ) and Tg2576 + Trolox (violet, $n=6$ ) dentate GCs estimated from Fig. $7 \mathrm{~b}$ (solid bars). The $\kappa_{E}$ values were also estimated from the plot of $1 /$ amplitude versus $\kappa_{B}$ (open bars). The dashed line (red) indicates the $\kappa_{E}$ value of CBKO GCs reported previously ${ }^{3}$. $\mathbf{d}$ (left) Time course of fura-2 in CBKO slices pretreated with Trolox for $1 \mathrm{hr}$. Scale bar: $100 \mathrm{nM}\left[\mathrm{Ca}^{2+}\right], 2 \mathrm{~s}$. (right) Plots of time constants for the decay phases of CaTs as a function of incremental $\mathrm{Ca}^{2+}$ binding ratios of fura-2 $\left(\kappa_{B}\right)$. e Mean values for $\kappa_{E}$ from CBKO with or without Trolox dentate GCs. The $\kappa_{\mathrm{E}}$ values of Trolox $(-)$ were adapted from a previous study ${ }^{3}$, and those of Trolox $(+)$ were estimated from Fig. $7 \mathrm{~d}$. Data are represented as the mean \pm SEM. ${ }^{* *} P<0.01,{ }^{* *} P<0.001$, N.S. not significant by Student's $t$ test. 
Tg2576 GCs: $211.4 \pm 19.4, n=7, P=0.000081$, Fig. 8c). Notably, the $K_{E}$ value estimated in Tg2576 GCS is comparable to that in CBKO GCs reported previously $(210.9 \pm 4.8$, red dashed line, Fig. $8 \mathrm{C})^{3}$. These results suggest that reduced $\mathrm{Ca}^{2+}$ buffering in Tg2576 GCs may be attributable to impaired $C B$ function.

$C B$ has two $\mathrm{N}$-terminal cysteine residues that undergo redoxdriven structural changes, and oxidized $\mathrm{CB}$ has a lower $\mathrm{Ca}^{2+}$ binding affinity than reduced $\mathrm{CB}^{40}$. We previously showed that mitochondrial reactive oxygen species (ROS) production is increased in the dentate GCs of 1- to 2-month-old Tg2576 mice, leading to depolarization of the mitochondrial potential, which was reversed by the antioxidant Trolox ${ }^{26}$. To test the possibility that oxidative stress induces the oxidation of $C B$ to compromise the $\mathrm{Ca}^{2+}$ buffering capacity, we examined whether the decreased $\mathrm{K}_{\mathrm{E}}$ in Tg2576 GCs was restored by antioxidant treatment. When hippocampal slices obtained from Tg2576 mice were incubated in Trolox $(500 \mu \mathrm{M})$ for $1 \mathrm{~h}$, the $\mathrm{K}_{\mathrm{E}}$ value of Tg2576 GCs was $322.98 \pm$ 30.2 (violet, estimated from the $\tau$ vs $K_{B}$ plots, Fig. 8a), which was not significantly different from the $K_{E}$ value of WT GCs (blue, Fig. $8 \mathrm{a}, P=0.53941)$. To confirm whether the effect of Trolox on $\mathrm{K}_{\mathrm{E}}$ in the Tg2576 GCs was indeed attributable to the protection of calbindin from oxidation, we tested the effect of Trolox on $\mathrm{K}_{E}$ in the CBKO GCs. Incubation of hippocampal slices obtained from CBKO mice with Trolox treatment for $1 \mathrm{~h}$ did not affect $\mathrm{K}_{\mathrm{E}}$ in $\mathrm{CBKO}$ GCs (Fig. 8d, e), suggesting that Trolox did not have an impact on $\mathrm{Ca}^{2+}$ buffer capacity originating from $\mathrm{Ca}^{2+}$ buffers other than calbindin. Reduced $\mathrm{Ca}^{2+}$ buffering and its restoration by Trolox in Tg2576 GCs suggest that CB function is impaired by oxidative stress.

\section{DISCUSSION}

The roles of endogenous $\mathrm{Ca}^{2+}$ buffers in the brain have been investigated mostly by analyzing the phenotypes of mice either lacking or overexpressing one of the $\mathrm{Ca}^{2+}$ buffers ${ }^{1}$. Mice with reduced $C B$ expression show deficits in memory and hippocampal long-term potentiation ${ }^{41}$, reduced short-term facilitation ${ }^{42}$, and impaired motor coordination ${ }^{1,43}$. In contrast, the overexpression of CB in DG GCs was shown to alter mossy fiber presynaptic function and impair hippocampal-dependent memory ${ }^{44}$. These data suggest that proper levels of CB are critical for neuronal activity control. However, the mechanisms underlying the involvement of $\mathrm{CB}$ in these phenotypes are largely unknown. In this study, we investigated the cellular and molecular mechanisms underlying the excitability changes in dentate GCs in CBKO mice and found that $\mathrm{Ca}^{2+}$ dysregulation caused by the loss of CB induces Kv4.1 downregulation, leading to hyperexcitability in dentate GCs. In addition, we observed impaired pattern separation in CBKO mice. These results, together with previous results showing that mice with selective depletion of Kv4.1 in the DG exhibit impaired pattern separation ${ }^{25}$, highlight the importance of the low excitability of dentate GCs in pattern separation.

$C B$ loss in dentate GCs has been shown to be tightly linked to $A D$-related cognitive deficits ${ }^{8}$. CB loss is also a well-known feature of temporal lobe epilepsy ${ }^{45-47}$. Since neuronal hyperactivity is also associated with $A D$, it has been suggested that $C B$ loss is a consequence of neuronal hyperactivity. However, the possibility that CB loss is not merely an epiphenomenon of these diseases but causally related to DG dysfunction remains to be elucidated. In this respect, CBKO mice can be a useful model for studying the pathophysiological significance of CB loss in various diseases. In this study, we proposed a causal link between $\mathrm{Ca}^{2+}$ buffering deficits and hyperexcitability of the DG, which leads to cognitive deficits. Furthermore, we identified the molecular mechanism by which $\mathrm{Ca}^{2+}$ buffering deficits lead to neuronal hyperexcitability. We showed that $C B$ depletion or overexpression, respectively, in HT22 cells decreased or increased the level of surface Kv4.1 along with p-CaMKII levels (Fig. 5a, b). Furthermore, pharmacological inhibition of CaMKII reduced Kv4.1 surface expression (Fig. 5c), suggesting that Kv4.1 trafficking to the surface membrane is regulated by CaMKII-dependent phosphorylation. We further identified a phosphorylation site in Kv4.1 that was critical for channel trafficking (Fig. 7). However, it is unclear how reduced $\mathrm{Ca}^{2+}$ buffering inhibited CaMKII activity, since reduced $\mathrm{Ca}^{2+}$ buffering was expected to increase cytosolic $\mathrm{Ca}^{2+}$ levels, and CaMKII activity was expected to increase at high $\mathrm{Ca}^{2+}$. To investigate this, we focused on another $\mathrm{Ca}^{2+}$-dependent enzyme that can act in the opposite way to kinase, calcineurin, a $\mathrm{Ca}^{2+}$ dependent phosphatase, and confirmed that reduced CaMKII activity and reduced Kv4.1 surface expression were restored, at least in part, with the pharmacological inhibition of calcineurin (Fig. 5d). These results suggest that $\mathrm{Ca}^{2+}$ dysregulation caused by CBKO resulted in an abnormal balance between $\mathrm{Ca}^{2+}$-dependent protein phosphatase and $\mathrm{Ca}^{2+}$-dependent protein kinase, causing a decrease in Kv4.1 phosphorylation, which is crucial for the surface localization of Kv4.1.

Protein phosphorylation and dephosphorylation are two essential mechanisms that regulate many functional proteins, such as enzymes, receptors, and ion channels. In the brain, $\mathrm{Ca}^{2+}$ dependent kinases and phosphatases play key roles in the activity-dependent regulation of neuronal functions. In particular, their roles in synaptic plasticity are well-known. A small increase in $\mathrm{Ca}^{2+}$ activates phosphatases, leading to long-term depression, while a higher increase in $\mathrm{Ca}^{2+}$ activates kinases, leading to longterm potentiation ${ }^{48}$. These results imply that $\mathrm{Ca}^{2+}$ signals are translated into the balance between $\mathrm{Ca}^{2+}$-dependent kinases and phosphatases, thus determining the phosphorylation states of synaptic proteins to regulate synaptic plasticity. Activitydependent regulation of ion channels through the balancing of $\mathrm{Ca}^{2+}$-dependent kinases and phosphatases has also been well documented. Activity-dependent downregulation of Kv1.2 activity in CA3 pyramidal neurons is mediated by $\mathrm{Ca}^{2+}$ - and Src family kinase-dependent endocytosis, which is facilitated by $\mathrm{Zn}^{2+}$ mediated suppression of tyrosine phosphatase ${ }^{49,50}$. The surface expression of Kv4.2 and endogenous A-type $\mathrm{K}^{+}$currents in hippocampal neurons was increased by the introduction of constitutively active CaMKII ${ }^{51}$. Taken together, these and our results suggest that the phosphorylation-dependent surface localization of $\mathrm{Kv}$ channels, rather than their expression, might be an important regulatory mechanism modulating neuronal activity. However, we found that the levels of surface Kv4.2 proteins were not altered by the CB levels (Fig. 5a, b). Further studies are needed to clarify the difference between CaMKIIdependent regulation of Kv4.1 and Kv4.2. It is possible that the increase in CaMKII activity due to CB expression is not sufficient to increase Kv4.2 phosphorylation to promote surface trafficking. We performed experiments without applying specific stimuli that are usually used in synaptic plasticity experiments to promote $\mathrm{Ca}^{2+}$ influx, while previous studies mainly focused on the role of $\mathrm{Ca}^{2+}$ dependent kinases and phosphatases in activity-dependent regulation. Therefore, our results represent the impact of the balance between $\mathrm{Ca}^{2+}$-dependent kinases and phosphatases on the phosphorylation states of Kv4.1 at resting $\mathrm{Ca}^{2+}$ levels. It remains to be investigated how the Kv4.1 phosphorylation state is changed upon stimulation, contributing to the activity-dependent regulation of GC excitability.

It has been established that CaMKII is dysregulated in the hippocampus of patients with $A D^{52}$. Key findings include reduced autophosphorylation of CaMKII in the hippocampus and frontal cortex of patients with $\mathrm{AD}^{53}$, alterations in the subcellular localization of autophosphorylated CaMKII in the CA3 and DG of the AD-affected brain ${ }^{18}$, and inhibition of CaMKII activation by amyloid $\beta^{54}$. However, it is still unclear how this dysregulation occurs. In a recent study, we showed that Tg2576 mice exhibited impaired pattern separation and hyperexcitable DG at the early preclinical stage $\mathrm{s}^{39}$. These findings are comparable to those 
observed in CBKO mice in the present study. The similar phenotypes of Tg2576 and CBKO mice suggest that they share a common mechanism, and we found that $\mathrm{Ca}^{2+}$ buffering capacity is severely reduced in GCs from Tg2576 mice (Fig. 8). Considering that CaMKII activation is inhibited by CB depletion (Fig. 5), reduced $\mathrm{Ca}^{2+}$ buffering capacity in Tg2576 GCs may contribute, at least in part, to dysregulated CaMKII signaling in AD. It is interesting to note that mice lacking CaMKII or calcineurin exhibit multiple abnormal behaviors related to schizophrenia ${ }^{11,55}$. These results together with the present study support the view that $\mathrm{Ca}^{2+}$ buffering deficits are causally related to hyperexcitable DG and cognitive deficits. However, abnormal excitability and $C B$ depletion in the DG were also reported in CaMKII-deficient mice ${ }^{11}$, suggesting the possibility that $C B$ expression is regulated by CaMKII. It is possible that CaMKII activity is regulated by $\mathrm{Ca}^{2+}$ and that activated CaMKII, in turn, regulates various mechanisms that regulate $\mathrm{Ca}^{2+}$ homeostasis, including $\mathrm{CB}$ expression. Close interrelationships between $\mathrm{Ca}^{2+}$ homeostasis and the balance between excitation and inhibition may be the most important features underlying normal brain functions. Considering that numerous $\mathrm{Ca}^{2+}$ buffers are present in neurons, future studies should examine the role of different $\mathrm{Ca}^{2+}$ buffers in this relationship.

\section{REFERENCES}

1. Schwaller, B. The use of transgenic mouse models to reveal the functions of $\mathrm{Ca} 2+$ buffer proteins in excitable cells. Biochimica et. Biophysica Acta (BBA)-Gen. Subj. 1820, 1294-1303 (2012)

2. Celio, M. Calbindin D-28k and parvalbumin in the rat nervous system. Neuroscience 35, 375-475 (1990).

3. Lee, S. H., Ho, W.-K. \& Lee, S.-H. Characterization of somatic Ca2+ clearance mechanisms in young and mature hippocampal granule cells. Cell Calcium 45, 465-473 (2009).

4. Blatow, M., Caputi, A., Burnashev, N., Monyer, H. \& Rozov, A. Ca2+ buffer saturation underlies paired pulse facilitation in calbindin-D28k-containing terminals. Neuron 38, 79-88 (2003).

5. lacopino, A., Christakos, S., Modi, P. \& Altar, C. Nerve growth factor increases calcium binding protein (calbindin-D28K) in rat olfactory bulb. Brain Res. 578, 305-310 (1992).

6. lacopino, A., Christakos, S., German, D., Sonsalla, P. \& Altar, C. Calbindin-D28Kcontaining neurons in animal models of neurodegeneration: possible protection from excitotoxicity. Mol. brain Res. 13, 251-261 (1992).

7. lacopino, A. M. \& Christakos, S. Specific reduction of calcium-binding protein (28kilodalton calbindin-D) gene expression in aging and neurodegenerative diseases. Proc. Natl Acad. Sci. USA 87, 4078-4082 (1990).

8. Palop, J. J. et al. Neuronal depletion of calcium-dependent proteins in the dentate gyrus is tightly linked to Alzheimer's disease-related cognitive deficits. Proc. Natl Acad. Sci. USA 100, 9572-9577 (2003).

9. Stefanits, H., Ebetsberger-Dachs, G., Weis, S. \& Haberler, C. Medulloblastoma with multi-lineage differentiation including myogenic and melanotic elements: a case report with molecular data. Clin. Neuropathol. 33, 122-127 (2014).

10. Altar, C. A. et al. Deficient hippocampal neuron expression of proteasome, ubiquitin, and mitochondrial genes in multiple schizophrenia cohorts. Biol. Psychiatry 58, 85-96 (2005).

11. Yamasaki, N. et al. Alpha-CaMKII deficiency causes immature dentate gyrus, a novel candidate endophenotype of psychiatric disorders. Mol. Brain 1, 6 (2008).

12. Walton, N. et al. Detection of an immature dentate gyrus feature in human schizophrenia/bipolar patients. Transl. Psychiatry 2, e135-e135 (2012).

13. Li, J.-T. et al. Suppressed calbindin levels in hippocampal excitatory neurons mediate stress-induced memory loss. Cell Rep. 21, 891-900 (2017).

14. Bayer, K. U. \& Schulman, H. CaM kinase: still inspiring at 40. Neuron 103, 380-394 (2019).

15. Hund, T. J. et al. A $\beta$ IV-spectrin/CaMKII signaling complex is essential for membrane excitability in mice. J. Clin. Investig. 120, 3508-3519 (2010).

16. Zybura, A. S., Baucum, A. J., Rush, A. M., Cummins, T. R. \& Hudmon, A. CaMKII enhances voltage-gated sodium channel Nav1. 6 activity and neuronal excitability. J. Biol. Chem. 295, 11845-11865 (2020).

17. Küry, S. et al. De novo mutations in protein kinase genes CAMK2A and CAMK2B cause intellectual disability. Am. J. Hum. Genet. 101, 768-788 (2017).

18. Reese, L. C., Laezza, F., Woltjer, R. \& Taglialatela, G. Dysregulated phosphorylation of $\mathrm{Ca} 2+/$ calmodulin-dependent protein kinase $\mathrm{II}-\mathrm{a}$ in the hippocampus of subjects with mild cognitive impairment and Alzheimer's disease. J. Neurochem. 119, 791-804 (2011).

19. Winder, D. G. \& Sweatt, J. D. Roles of serine/threonine phosphatases in hippocampal synaptic plasticity. Nat. Rev. Neurosci. 2, 461-474 (2001).

20. Kim, J. H. et al. Overexpression of calbindin-D28K in hippocampal progenitor cells increases neuronal differentiation and neurite outgrowth. FASEB J. 20, 109-111 (2006).

21. Leutgeb, J. K., Leutgeb, S., Moser, M. B. \& Moser, E. I. Pattern separation in the dentate gyrus and CA3 of the hippocampus. Science 315, 961-966 (2007).

22. O'Reilly, R. C. \& McClelland, J. L. Hippocampal conjunctive encoding, storage, and recall: avoiding a trade-off. Hippocampus 4, 661-682 (1994).

23. Treves, A. \& Rolls, E. T. Computational analysis of the role of the hippocampus in memory. Hippocampus 4, 374-391 (1994).

24. Rolls, E. T. The mechanisms for pattern completion and pattern separation in the hippocampus. Front. Syst. Neurosci. 7, 74 (2013).

25. Kim, K.-R. et al. Kv4. 1, a key ion channel for low frequency firing of dentate granule cells, is crucial for pattern separation. J. Neurosci. 40, 2200-2214 (2020).

26. Lee, S. H. et al. Impaired short-term plasticity in mossy fiber synapses caused by mitochondrial dysfunction of dentate granule cells is the earliest synaptic deficit in a mouse model of Alzheimer's disease. J. Neurosci. 32, 5953-5963 (2012).

27. Neher, E. Usefulness and limitations of linear approximations to the understanding of Ca++ signals. Cell Calcium 24, 345-357 (1998).

28. Neher, E. \& Augustine, G. Calcium gradients and buffers in bovine chromaffin cells. J. Physiol. 450, 273-301 (1992).

29. Cesarini, E. et al. Melatonin protects hippocampal HT22 cells from the effects of serum deprivation specifically targeting mitochondria. PLOS ONE 13, e0203001 (2018).

30. Pyun, J.-H. et al. Cardiac specific PRMT1 ablation causes heart failure through CaMKII dysregulation. Nat. Commun. 9, 1-15 (2018).

31. Jeong, M.-H. et al. PRMT1 suppresses ATF4-mediated endoplasmic reticulum response in cardiomyocytes. Cell Death Dis. 10, 1-13 (2019).

32. Choi, S. et al. Skeletal muscle-specific Prmt1 deletion causes muscle atrophy via deregulation of the PRMT6-FOXO3 axis. Autophagy 15, 1069-1081 (2019).

33. Bae, J. H. et al. Satellite cell-specific ablation of Cdon impairs integrin activation, FGF signalling, and muscle regeneration. J. Cachexia Sarcopenia Muscle 11, 1089-1103 (2020)

34. McHugh, T. J., Jones, M. W., Quinn, J. J., Balthasar, N., Coppari, R., Elmquist, J. K., et al. Dentate gyrus NMDA receptors mediate rapid pattern separation in the hippocampal network. Science. 317, 94-99 (2007).

35. McNaughton, B. L. \& Nadel, L. Hebb-Marr networks and the neurobiological representation of action in space. Neuroscience and connectionist theory, 1-63 (1990).

36. Kim, S., Mátyás, F., Lee, S., Acsády, L. \& Shin, H.-S. Lateralization of observational fear learning at the cortical but not thalamic level in mice. Proc. Natl Acad. Sci. USA 109, 15497-15501 (2012).

37. Rolls, E. T. \& Kesner, R. P. A computational theory of hippocampal function, and empirical tests of the theory. Prog. Neurobiol. 79, 1-48 (2006).

38. Ohno, M., Sametsky, E. A., Silva, A. J. \& Disterhoft, J. F. Differential effects of aCaMKII mutation on hippocampal learning and changes in intrinsic neuronal excitability. Eur. J. Neurosci. 23, 2235-2240 (2006).

39. Kim, K.-R. et al. Impaired pattern separation in Tg2576 mice is associated with hyperexcitable dentate gyrus caused by Kv4. 1 downregulation. Mol. Brain 14, 1-14 (2021).

40. Cedervall, T. et al. Redox sensitive cysteine residues in calbindin D28k are structurally and functionally important. Biochemistry 44, 684-693 (2005).

41. Molinari, S. et al. Deficits in memory and hippocampal long-term potentiation in mice with reduced calbindin D28K expression. Proc. Natl Acad. Sci. USA 93, 8028-8033 (1996).

42. Yang, C. H., Lee, K. H., Ho, W. K. \& Lee, S. H. Inter-spike mitochondrial Ca2+ release enhances high frequency synaptic transmission. J. Physiol. 599, 1567-1594 (2021).

43. Airaksinen, M. S. et al. Ataxia and altered dendritic calcium signaling in mice carrying a targeted null mutation of the calbindin D28k gene. Proc. Natl Acad. Sci. USA 94, 1488-1493 (1997).

44. Dumas, T., Powers, E., Tarapore, P. \& Sapolsky, R. Overexpression of calbindin D28k in dentate gyrus granule cells alters mossy fiber presynaptic function and impairs hippocampal-dependent memory. Hippocampus 14, 701-709 (2004).

45. Carter, D. S., Harrison, A. J., Falenski, K. W., Blair, R. E. \& DeLorenzo, R. J. Long-term decrease in calbindin-D28K expression in the hippocampus of epileptic rats following pilocarpine-induced status epilepticus. Epilepsy Res. 79, 213-223 (2008).

46. Maglóczky, Z., Halasz, P., CZIRJÁK, J. V. S. \& Freund, T. Loss of calbindin-D, immunoreactivity from dentate granule cells in human temporal lobe epilepsy. Neuroscience 76, 377-385 (1997). 
47. Nägerl, U. V. et al. Surviving granule cells of the sclerotic human hippocampus have reduced $\mathrm{Ca} 2+$ influx because of a loss of calbindin-D28k in temporal lobe epilepsy. J. Neurosci. 20, 1831-1836 (2000).

48. Lisman, J. A mechanism for the Hebb and the anti-Hebb processes underlying learning and memory. Proc. Natl Acad. Sci. USA 86, 9574-9578 (1989).

49. Eom, K. et al. Intracellular Zn2+ signaling facilitates mossy fiber input-induced heterosynaptic potentiation of direct cortical inputs in hippocampal CA3 pyramidal cells. J. Neurosci. 39, 3812-3831 (2019).

50. Hyun, J. H., Eom, K., Lee, K. H., Ho, W. K. \& Lee, S. H. Activity-dependent downregulation of $\mathrm{D}$-type $\mathrm{K}+$ channel subunit $\mathrm{Kv} 1.2$ in rat hippocampal CA3 pyramidal neurons. J. Physiol. 591, 5525-5540 (2013).

51. Varga, A. W. et al. Calcium-calmodulin-dependent kinase II modulates Kv4. 2 channel expression and upregulates neuronal A-type potassium currents. J. Neurosci. 24, 3643-3654 (2004).

52. Ghosh, A. \& Giese, K. P. Calcium/calmodulin-dependent kinase II and Alzheimer's disease. Mol. Brain 8, 1-7 (2015).

53. Amada, N., Aihara, K., Ravid, R. \& Horie, M. Reduction of NR1 and phosphorylated Ca2+/calmodulin-dependent protein kinase II levels in Alzheimer's disease. Neuroreport 16, 1809-1813 (2005).

54. Zhao, D., Watson, J. B. \& Xie, C.-W. Amyloid $\beta$ prevents activation of calcium/ calmodulin-dependent protein kinase II and AMPA receptor phosphorylation during hippocampal long-term potentiation. J. Neurophysiol. 92, 2853-2858 (2004).

55. Miyakawa, T. et al. Conditional calcineurin knockout mice exhibit multiple abnormal behaviors related to schizophrenia. Proc. Natl Acad. Sci. USA 100, 8987-8992 (2003).

\section{ACKNOWLEDGEMENTS}

This research was supported by National Research Foundation grants from the Korean Ministry of Science and ICT (2017R1A2B2010186 and 2020R1A2B5B02002070 to W.-K.H.).

\section{AUTHOR CONTRIBUTIONS}

K.-R.K., H.-J.J., Y.K., S.Y.L., and H.-J.K. conducted the experiments. Y.K., S.-H.L., H.C., J.-S. K., and W.-K.H. designed the experiments and wrote the paper.

\section{COMPETING INTERESTS}

The authors declare no competing interests.

\section{ADDITIONAL INFORMATION}

Correspondence and requests for materials should be addressed to J.-S.K. or W.-K.H.

Reprints and permission information is available at http://www.nature.com/ reprints

Publisher's note Springer Nature remains neutral with regard to jurisdictional claims in published maps and institutional affiliations.

Open Access This article is licensed under a Creative Commons Attribution 4.0 International License, which permits use, sharing, adaptation, distribution and reproduction in any medium or format, as long as you give appropriate credit to the original author(s) and the source, provide a link to the Creative Commons license, and indicate if changes were made. The images or other third party material in this article are included in the article's Creative Commons license, unless indicated otherwise in a credit line to the material. If material is not included in the article's Creative Commons license and your intended use is not permitted by statutory regulation or exceeds the permitted use, you will need to obtain permission directly from the copyright holder. To view a copy of this license, visit http://creativecommons. org/licenses/by/4.0/.

(c) The Author(s) 2021 